\title{
Pseudomonas aeruginosa - Pathogenesis and Pathogenic Mechanisms
}

\author{
Alaa Alhazmi ${ }^{1,2}$ \\ ${ }^{1}$ Department of Biology, Lakehead University, Thunder Bay, Ontario, Canada \\ ${ }^{2}$ Department of Medical Laboratory Technology, Jazan University, Jazan, Kingdom of Saudi Arabia \\ Correspondence: Alaa Alhazmi, Department of Biology, Lakehead University, 955 Oliver Road, Thunder Bay, \\ ON, P7B 5E1, Canada. Tel: 1-807-766 7428. Email: aalhazmi@lakeheadu.ca
}

Received: December 9, 2014 Accepted: January 3, 2015 Online Published: February 3, 2015

doi:10.5539/ijb.v7n2p44 URL: http://dx.doi.org/10.5539/ijb.v7n2p44

\begin{abstract}
Pseudomonas aeruginosa is a common bacterium, Gram-negative opportunistic pathogen capable of infecting humans with compromised natural defenses and causing severe pulmonary disease. It is one of the leading pathogen associated with nosocomial infections. It has a vast arsenal of pathogenicity factors that are used to interfere with host defenses. Pathogenesis in P. aeruginosa facilitates adhesion, modulate or disrupt host cell pathways, and target the extracellular matrix. The propensity of $P$. aeruginosa to form biofilms further protects it from antibiotics and the host immune system. $P$. aeruginosa is intrinsically resistant to a large number of antibiotics and can be acquired resistance to many others, making treatment difficult. $P$. aeruginos a provokes a potent inflammatory response during the infectious process. The majority of mortalities in immunocompromised patients; cystic fibrosis, can be attributed to the progressive decline of lung function resulting from chronic infection by pathogens such as $P$. aeruginosa. Antibiotic treatment of chronic $P$. aeruginosa infections may temporarily suppress symptoms; however, they do not eradicate the pathogen. Lung diseases caused by $P$. aeruginosa are a leading cause of death in immunocompromised individuals as well as in children. Although immunocytes recruitment is critical to augment the host defense, excessive neutrophil accumulation results in life-threatening diseases, such as acute lung injury, as well as acute respiratory distress syndrome. Several virulence factors have been studied for their roles as potential vaccine candidate, although there is currently no clinically accepted vaccine. Understanding host-pathogen interaction is critical for the development of effective therapeutic strategies to control the damage in the lung.
\end{abstract}

Keywords: Pseudomonas aeruginosa, nosocomial infection, virulence factors, antibiotic resistance, cystic fibrosis

$P$. aeruginosa is a motile, non-fermenting, Gram-negative organism belonging to the family Pseudomonadaceae. In 1850s, Sédillot observed that a blue-green discharge was frequently present and associated with infection in surgical wound dressings (Lyczak, Cannon, \& Pier, 2000). The infectious organism has a rod-shaped and blue-green pigmented bacterium (Lartigau, 1898). By 1961, the ability of this organism to cause both severe acute and chronic infections was recognized (Freeman, 1916). In 1960s, P. aeruginosa emerged as an important human pathogen (Doggett, 1979). Despite anti-pseudomonas activity being one of the pharmaceutical drug discoveries for several decades. It remains one of the most recalcitrant and difficult to treat organisms. Accordingly, $P$. aeruginosa result has achieved Superbug status.

At 6.3 million base pair (Mbp), P. aeruginosa genome is markedly as a large genome (encoding 5567 genes) compared to $4.64 \mathrm{Mbp}$ (4279 genes) in Escherichia coli K12, $2.81 \mathrm{Mbp}$ (2594 genes) in Staphylococcus aureus N315, and $1.83 \mathrm{Mbp}$ (1714 genes) in Haemophilus influenza Rd. Also, the proportion of predicted regulatory genes in $P$. aeruginosa genome is greater than in all other sequenced bacterial genomes (Stover et al., 2000; Lambert, 2002), thus lending to its adaptability to varying environments. P. aeruginosa has a broad range of growth substrate, minimal nutrient requirements; non-fastidious microorganisms (Favero, Carson, Bond, \& Petersen, 1971). The organism is tolerant of temperatures as high as $50^{\circ} \mathrm{C}$ and is capable of growing under aerobic conditions, as well as anaerobic conditions (van Hartingsveldt \& Stouthamer, 1973). Despite possessing a large number of virulence factors. In spite of this, $P$. aeruginosa is truly a challenging pathogen in the hospital setting as it is resistant to many antibiotics. Also, it is capable of forming hardy biofilms, both within the body and on the surfaces of medical instruments (Consterton, Stewart, \& Greenberg, 1999; Hancock, 1998, Moreau-Marquis, Stanton, \& O'Toole, 2008). P. aeruginosa continues to be problematic from a treatment perspective. 
P. aeruginosa is armed with potent virulence factors. Although ubiquitously present in the environment, $P$. aeruginosa never causes disease in an immunocompetent host as the immune system effectively prevents the infection. However, the pathogen causes severe infections in Cystic Fibrosis (CF) patients. In CF, a genetic defect in lung innate immunity underlies the development of persistent infection with $P$. aeruginosa that gradually leads to irreversible tissue damage. Several conserved microbial structures in $P$. aeruginosa are recognized by Toll-like receptors (TLRs) and NOD-like receptors (NLRs); which have been implicated in activating the host innate immune responses to P. aeruginosa (DiMango, Zar, Bryan, \& Prince, 1995; Skerrett, Wilson, Liggitt, \& Hajjar, 2007).

There are a number of clinical diseases associated with P. aeruginosa infection. However, P. aeruginosa is an opportunistic organism infecting; burn, $\mathrm{CF}$, leukemic, transplant, neutropenic, long-term urinary catheters, and diabetic patients as well intravenous drug abusers.

\section{Nosocomial Infection Due to $P$. aeruginosa}

Nosocomial (hospital-acquired) infections are those not present or incubating at the time of hospital admission, but usually develop post-admission. The 2006-7 report by National Healthcare Safety Network (NHSN) at the Centers for Disease Control and Prevention (CDC) ranked P. aeruginosa as the sixth most common healthcare associated pathogen-causing infection. Also, it is typically found at even higher rank in studies focused on the intensive care unit (ICU). The NHSN reports that in United States in 2006-7, 8\% of all hospital-associated infections were due to $P$. aeruginosa, with $P$. aeruginosa causing $3 \%$ of central line-associated bloodstream infections, $6 \%$ of surgical site infections, $10 \%$ of catheter-associated urinary tract infection and $16 \%$ of ventilator-associated pneumonia (VAP) infections (Hidron et al., 2008). Mechanical ventilation, antibiotic therapy, surgery, and chemotherapy are the major predisposing factors contributing to the acquisition of a $P$. aeruginosa infection in the hospital (Thuong et al., 2003). It is worth noting however that difficulties in treatment of such infections and the associated morbidity and mortality, have made P. aeruginosa on of the most feared hospital pathogens.

\subsection{Burn Wound Infections}

P. aeruginosa is the leading cause of invasive infections in burn patients; $75 \%$ of all deaths in patients with severe burn are related to sepsis from invasive burn wound infection (Baker, Miller, \& Trunkey, 1979; Bang, Sharma, Sanyal, \& Najjadah 2002; Barrow, Spies, Barrow, \& Herndom, 2004). In addition to wounded skin injury, inhalation injury is common in burn patients. This results in edema and sloughing of the respiratory tract mucosa and impairment of the normal mucociliary clearance mechanism, thus making these patients more susceptible to upper respiratory tract infections as well as $P$. aeruginosa pneumonia (Church, Elsayed, Reid, Winston, \& Lindsay, 2006).

Although Gram-positive organisms such as Staphylococcus aureus and Streptococcus pyrogens are typically the first microorganisms to colonize the site of infection, after that other microbes including P. aeruginosa being to colonize these wounds (Altoparlak, Erol, Akcay, Celebi, \& Kadanali, 2004; MacMillan, 1980). Success with early wound excision practices was shown to contribute to the prevention of invasive infections disseminating from the wound site (Barret \& Herndon, 2003). Animal studies of partial-thickness cutaneous burns showed that mature biofilms could develop in 48 to 72 hours, indicating a major potential source of further difficulties in antimicrobial therapy at these sites (Trafny, 1998).

In addition to the $P$. aeruginosa virulence factors that undoubtedly contribute to the success of $P$. aeruginos $a$ as a pathogen in the burn patients, described later, the impairment of host immunity, beyond simple loss of the skin's physical barrier, plays a role in enhancing susceptibility to infection. Recent studies have demonstrated that thermal injury causes impaired production of the host defense peptides $\beta$-defensins in the tissues surrounding the wound. These immunomodulatory peptides have been proposed to play an important role in primary defense against $P$. aeruginosa and synthetic $\beta$-defensin was recently shown to be protective against $P$. aeruginosa infection in a burned mouse model (Kobayashi et al., 2008).

\subsection{Bacteremia}

$P$. aeruginosa is among the five leading causes of nosocomial bacteremia and frequently leads to sepsis. In the 1960 s and early 1970s, aminoglycosides and polymyxins were the only options for treatment of $P$. aeruginosa bacteremia but were found to be fairly ineffective for these infections. Mortality of greater than $50 \%$ was reported when mortality was used as the end point (Fishman \& Armstrong, 1972; Whitecar, Luna, \& Bodey, 1970), and was as high as $70 \%$ in febrile neutropenic patients (Bodey, Jadeja, \& Elting, 1985). Despite the introduction of effective anti-pseudomonal $\beta$-lactams and the associated reduction in mortality rates, $P$. aeruginosa bacteremia is still one of 
the most feared nosocomial infections. These infections are generally associated with higher mortality than with other infecting pathogens, and persistence, particularly related to device-related bacteremia, continues to plague patients (Rello, Ricart, Mirelis, Quintana, Gurgui, Net, \& Prats, 1994).

The main distinguishing feature of $P$. aeruginosa sepsis is the presence of ecthyma gangrenous, and these infarcted skin lesions occur only in markedly neutropenic patients (Pier \& Ramphal, 2005). When P. aeruginosa disseminates from a site of local infection, it gains access to the bloodstream by breaking down epithelial and endothelial tissue barriers (Kurahashi et al., 1999). To evade the bactericidal activity of the serum complement, P. aeruginosa produces a smooth lipopolysaccharide (LPS) (Hancock et al., 1983; Pier \& Ames, 1984); full-length $\mathrm{O}$ side-chain of the bacteria.

\subsection{Hospital-Associated Pneumonia}

The human respiratory tract presents a favorable environment to which $P$. aeruginosa has become particularly well adapted. $P$. aeruginosa has the formidable ability to cause both chronic infections in the lung of CF patients and acute nosocomial pneumonia (Blondel-Hill and Fryters, 2006). Animal model studies of P. aeruginosa pneumonia have demonstrated the involvement in virulence of proteases, flagella, pili and LPS O side chains as well as the delivery of the extracellular toxins ExoS, ExoT and ExoU via a type III secretion system (T3SS). For example, administration of anti-pcrV antibodies blocking the T3SS has been shown to offer protection against acute $P$. aeruginosa pneumonia when tested in animal studies (Faure et al., 2003; Shime et al., 2001).

\subsection{Ventilator-Associated Pneumonia}

P. aeruginosa is commonly found to be the first or second major pathogen causing VAP (Hidron et. al., 2008). It is the most common multidrug resistance pathogen involved in this disease and recovery rate of $P$. aeruginosa is increased with increased duration of mechanical ventilation. In addition to being amongst the most common pathogens causing VAP, $P$. aeruginosa is also amongst the most lethal pathogens, since reports suggest up to $70-80 \%$ mortality when the organism remains confined to the lung (Chastre \& Fagon, 2002), with directly attributable mortality rates reaching 38\% (Fagon et al., 1993).

\section{P. aeruginosa Infections in Cystic Fibrosis}

Cystic fibrosis (CF) is; an autosomal receive genetic disorder, the most common fatal genetic disease. CF is caused by a mutation in a gene on chromosome 7 known as CFTR (cystic fibrosis transmembrane conductance regulator). Most common mutant allele is $\Delta \mathrm{F} 508$ (or F508del) mutation, which is a three-nucleotide deletion of a phenylalanine residue and subsequent defective intracellular processing of the CFTR protein that is an important chloride channel (Bobadilla, Fine, \& Farrell, 2002). CF is affecting 1:2,500 in the Caucasian population (Ratjen $\&$ Doring, 2003). CF is multi-system disease, which affects mainly lung and digestive system. Most CF-related deaths are due to lung disease (Bobadilla, Fine, \& Farrell, 2002).

Mortality in this afflicted population is mainly attributed to chronic respiratory infections and the associated gradual deterioration of lung function. There are several pathogens known to play a role in CF lung infection, with Staphylococcus aureus and Haemophilus influenzae being the predominant pathogens colonizing in infancy and early childhood, and eventual replacement by $P$. aeruginosa. However, $P$. aeruginosa is often isolated from patients less than 2 years of age and is the most predominant concern in adults (Gibson, Burns, \& Ramsey, 2003; Hudson, Wielinski, \& Regelmann, 1993). Up to $90 \%$ of individuals suffering from CF become infected with $P$. aeruginosa during their lifetime, and this organism is the leading cause of morbidity and mortality among those patients. It is dominant pathogen in chronic lung infection in CF. In the majority of cases, colonization of the CF airway by $P$. aeruginosa leads to a chronic infection that is resistant to antimicrobial therapy (MacEachran et al., 2007; Döring et al., 2014). Chronic colonization and infection with $P$. aeruginosa is an inevitable reality for the majority of adults with $\mathrm{CF}$, as over $80 \%$ of adults over the age of 18 years return positive cultures for $P$. aeruginosa (Hodson, 2000). The nature of this disease is critical in understanding why $P$. aeruginosa dominates as the primary pathogen in CF patients and so host pathology is addressed below.

The defective gene involved in CF encodes for CFTR resulting in pathological changes in organs that express CFTR, including lungs. In a normal airway epithelial cell, the gene encoding for CFTR, regulates the transport of chloride, sodium, and water. Abnormalities of the CFTR gene product lead to a thick and dehydrated mucous secretion that impairs mucociliary clearance of bacterial pathogens (Collins, 1992). In the normal lung, the mucus layers function in binding and clearance of inhaled pathogen, and although the bacterial load can be quite high in the upper airways, the lower airways remain free of bacteria (Bals, Weiner, \& Wilson, 1999). Due to the characteristic thickened mucus associated with CF lung disease, and resulting an inability of ciliary beating to remove the mucus, invading pathogens become trapped in the mucus layer. As a result, a constant presence of 
bacteria with expression pathogen-associated molecular patterns (PAMPs) leads to chronic inflammation, consequently damaging the epithelial surface (Donaldson et al., 2006; Greene et al., 2005; Kolberg, Mossberg, Afzelius, Philipson, \& Camner, 1978).

A novel concept of host susceptibility emerged that the epithelial cells use CFTR as a receptor for internalization of $P$. aeruginosa and subsequent removal of bacteria from the airway surface (Pier, Grout, \& Zaidi, 1997; Pier et al., 1996). Accordingly, CFTR is considered as a pattern recognition molecule that extracts $P$. aeruginosa LPS from the organism's surface into epithelial cells (Schroeder et al., 2002). The prevention of CFTR-P. aeruginosa interactions led to decrease bacterial clearance and increased bacterial burdens in the lungs.

\subsection{Adaptation Occurring During Chronic Infection}

$\mathrm{CF}$ patients frequently become colonized in the upper airways by unrelated environmental isolates of $P$. aeruginosa (Salunkhe et al., 2005; Speert et al., 2002). During the process of infection, a number of adaptations occur leading to the characteristic persistence and antibiotic resistance of isolates found from chronic infection. Amongst the most common adaptations of $P$. aeruginosa found in CF isolates, is the conversion to mucoid phenotype due to overexpression of alginate (Govan \& Deretic, 1996). Environmental isolates usually present a non-mucoid phenotype, as $P$. aeruginosa penetrates the thickened mucus lining of the airways, travelling down the oxygen gradient, increased expression of alginate and a switch to a mucoid phenotype occur (Grimwood, 1992; Starner \& McCray, 2005). This phenotype often occurs coincidently with the establishment of chronic infection and becomes stabilized by regulatory mutations as described earlier. The mucoid form of $P$. aeruginosa is associated with $90 \%$ of $P$. aeruginosa $\mathrm{CF}$ infections compared to only $2 \%$ of $P$. aeruginosa non-CF infections (Doggett, 1969; Doggett, Harrison, \& Carter, 1971). This phenotype is often coordinately regulated with a loss of flagella by the alternative sigma factor AlgT (Tart, Wolfgang, \& Wozniak, 2005). The loss of flagella causes not only loss of motility, but also decreased activation of host inflammatory mediators (Cobb, Mychaleckyj, Wozniak, \& Lopez-Boado, 2004).

Other easily identified morphological adaptations of $P$. aeruginosa include the switch from smooth to rough colony morphology and the appearance of small colony variants. The rough colony morphology is representative of strains that have lost the LPS O-antigen (Hancock et al., 1983). As the O-antigen is the immunodominant portion of the LPS, this adaptation leads to a less virulent phenotype. It also makes rough isolates more susceptible to complement killing and perhaps explains in part why these organisms virtually never cause invasive infections. Modifications to the lipid A moiety of the LPS are also observed. These include the addition of palmitate, aminoarabinose and the retention of 3-hydroxydecanoate (Ernst et al., 2007). The small colony phenotype is less well understood but is of considerable interest as these isolates exhibit increased antibiotic resistance. Isolates exhibiting this phenotype have been found to be hyperpiliated with increased abilities in twitching and biofilm formation, and with decreased ability for swimming (Haussler et al., 2003).

Another phenotype of relevance to antimicrobial therapy and resistance is the hypermutator phenotype, which is frequently observed in CF isolates, but less commonly in nosocomial isolates of $P$. aeruginosa (Oliver, Canton, Campo, Baquero, \& Blazquez, 2000). This phenotype, characterized by an up to 1000 -fold increased mutation frequency, has been attributed to mutations in genes encoding DNA replication and repair mechanisms, such as mutS, mutL, and mutY. Most importantly, these hypermutator isolates can develop mutational resistance more readily during a course of antimicrobial therapy than do non-mutator isolates. The hypermutator phenotype can give rise to a variety of mixed morphologies within the lung, including those described above (Hogardt et al., 2007). These diverse populations can colonize or infect different compartments within the lung and often have variable antimicrobial susceptibilities with virulence properties (Foweraker, Laughton, Brown, \& Bilton, 2005; Irvin, Govan, Fyfe, \& Costerton, 1981; MacLeod et al., 2000; Pai \& Nahata, 2001).

Comparison of $P$. aeruginosa isolates from the CF lung to strains from non-CF patients showed clearly that CF isolates tend to demonstrate an overproduction of $\beta$-lactamase, loss of OprD and an overproduction of MexXY. This efflux pump overproduction leads to high-level aminoglycoside resistance and the overproduction of this and other efflux systems also lead to quinolone resistance, amongst which MexCD-OprJ was the most frequent (Henrichfreise, Wiegand, Pfister, \& Wiedemann, 2007).

\subsection{Antimicrobial Therapy for Treatment of P. aeruginosa}

P. aeruginosa isolates from CF patients frequently develop multi-drug resistance. Combination therapy can be used to avoid resistance development and to exploit the synergistic effects of the bactericidal antibiotics. The use of aerosols allows for drugs to be delivered directly to the lung in CF patients and a number of antibiotics including gentamicin, tobramycin, colistin, ceftazidime, carbenicillin aztreonam and amikacin have been 
administered as aerosols to CF patients, although approved formulation and adequate controlled studies have not been performed on most of these (Hodson, Penketh, \& Batten, 1981; Stead, Hodson, \& Batten, 1987).

\subsubsection{Antimicrobial Therapy for Colonization and Initial Infection}

Eradication of $P$. aeruginosa from the CF lung is possible only in the early stages of colonization. At this point, the bacterial load tends to be low, and the organism is non-mucoid and has not begun to undergo significant morphological changes. Aggressive antimicrobial treatment upon first isolation of $P$. aeruginosa has been demonstrated in most cases to delay and occasionally prevent the onset of chronic infections resulting in a better quality of life and a greater life expectancy (Nixon et al., 2001; Rosenfeld, Ramsey, \& Gibson, 2003). Successful eradicating is judged by the observation of at least three consecutive negative cultures at intervals of at least month. After one year of negative cultures following the onset of antimicrobial therapy, any isolation of $P$. aeruginosa is considered to represent a new isolate (Gibson, Burns, \& Ramsey, 2003). Aggressive antimicrobial use at the early stage has proven in certain cases to be successful, with a number of patients having remained culture negative for P. aeruginosa for several years after treatment (Frederiksen \& Hoiby, 1997; Ratjen, Doring, \& Nikolaizik, 2001).

\subsubsection{Antimicrobial Therapy for Chronic Infections}

Once chronic infection has been established by $P$. aeruginosa, the high bacterial load present in the lung, as well as the phenotypic changes occurring in the pathogen complicates antimicrobial therapy. The high bacterial load and thickened mucus are barriers to the attainment of sufficient exposure of the entire bacterial population to bactericidal concentrations of antibiotics (Mendelman et al., 1985). Administration of insufficient concentrations of antibiotics adds increased selective pressure for resistant phenotypes, thereby enhancing the diversity of the population, lending further difficulties to effective treatment (MacLeod et al., 2000; Pai \& Nahata, 2001).

Antimicrobial therapy is used during chronic infections in CF for two main purposes: maintenance therapy and treatment of acute exacerbations of infection (Doring et al., 2000). Maintenance therapy is recommended for CF patients with chronic $P$. aeruginosa infections in order to reduce bacterial load and maintain overall lung function. Unfortunately, a number of side effects are associated with long-term antimicrobial use including loss of hearing, increased cough, alterations of the voice, and the appearance of antibiotic resistant strains. The use of on/off cycles of intermittent drug administration led to the reduced occurrence of these side effects (Ramsey et al., 1999).

\section{Pathogenesis and Major Virulence Factors}

Pathogenesis in $P$. aeruginosa is mediated by multiple bacterial virulence factors that facilitate adhesion and/or disrupt host cell signaling pathways while targeting the extracellular matrix (Figure 1). P. aeruginosa stands out as a unique and threating organism as it is capable of causing severe invasive disease and of evading immune defenses causing persisting infections that are nearly impossible to eradicate (Pier \& Ramphal, 2005). The subsequent tissue damage, invasion, and dissemination of $P$. aeruginosa are likely attributed to the many virulence factors it produces. These virulence factors play an initial role in motility and adhesion to the epithelium. These virulence factors are thought to be critical for maximum virulence of $P$. aeruginosa; however, based on observations of diverse plant and animal models, the relative contribution of any given factor may vary with the type of infection (Preston et al., 1995; Rahme et al., 1997; Tamura, Suzuki, \& Sawada, 1992; Tamura, Suzuki, Kijima, Takahashi, \& Nakamura, 1992; Tang et al., 1996). Several of these virulence factors have also been studied for their roles as potential vaccine candidate although there is currently no general accepted vaccine The following section briefly outlines several prominent putative virulence factors produce by $P$. aeruginos $a$ and their proposed roles in contributing to disease.

\subsection{Lipopolysaccharide}

The LPS is a predominant component of the outer membrane of $P$. aeruginosa. Bacterial LPS typically consist of a hydrophobic domain known as lipid A (or endotoxin), a non-repeating core oligosaccharide, and a distal polysaccharide (or O-antigen) (Raetz \& Whitfield, 2002). The composition of O-antigen determines the serotypes of the $P$. aeruginosa isolate and currently there are 20 serotypes based on serological reactivity of the O-antigen (Liu \& Wang, 1990). LPS plays a prominent role in activation the host's innate (TLR4, NLRP1, NLRP2, and NLRP3) and adaptive (or acquired) immune responses; and, eventually causes dysregulated inflammation responses that contribute to morbidity and mortality (Heine, Rietschel, \& Ulmer, 2001).

Recognition of LPS occurs largely by TLR4-MD2-CD14 complex, which is present on many cell types including macrophages and dendritic cells. Recognition of lipid A also requires an accessory protein, LPS-binding protein (LBP), which converts oligomeric micelles of LPS to a monomer for delivery to CD14, 
which is high-affinity membrane protein that can also circulate in a soluble form (Poltorak et al., 1998; Wright, Ramos, Tobias, Ulevitch, \& Mathison, 1990; Shimazu et al., 1999; Qureshi et al., 1999; Hoshino et al., 1999). In addition, NLRs regulate both inflammation and pyroptosis. The activation of NLRs results in an assembly of complex structures called inflammasomes (Franchi, Muñoz-Planillo, \& Núñez, 2012). The NLRP1 inflammasome was first described in 2002 in human monocytes as a molecular compound that responds to LPS (Martinon, Burns, \& Tschopp, 2002). Many stimuli that trigger assembly of the inflammasomes have been described. LPS also reported to activate NLRP3 when administered in the presence of ATP (Stutz, Golenbock, \& Latz, 2009), as well as NLRP2 (Lamkanfi, \& Dixit, 2009). A number of LPS vaccines have been investigated for use in CF patients in phase II and III clinical trials; however, these have not been successful (Doring \& Pier, 2008; Hanessian, Regan, Watson, \& Haskell, 1971; Langford \& Hiller, 1984; Pennington, 1979; Pennington \& Miler, 1979). The LPS based vaccines provided little immunity and did not appear to protect the patients from infection with P. aeruginosa (Pier, 2003).

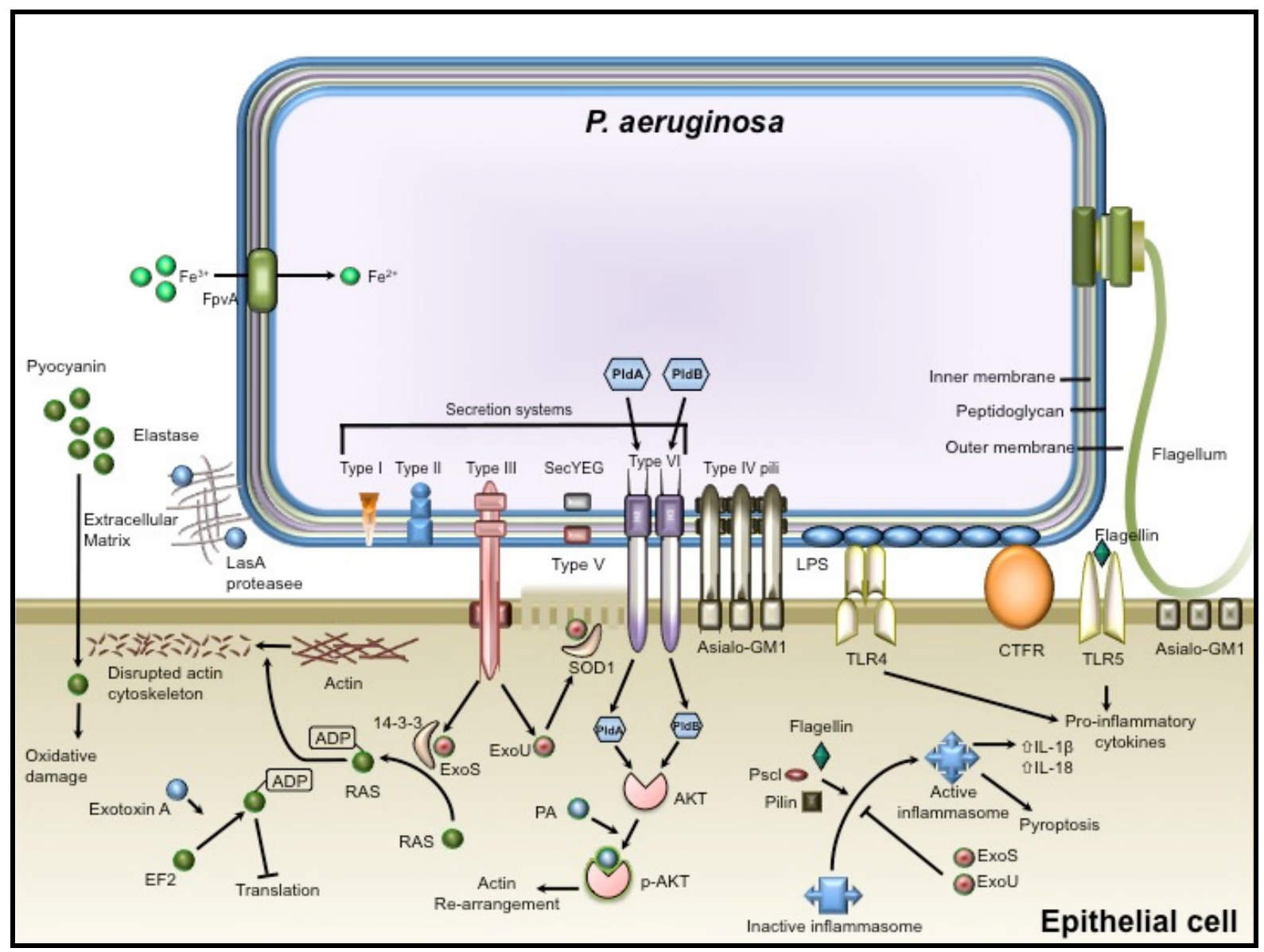

Figure 1. P. aeruginosa Pathogenesis and Major Virulence Factors

Pathogenesis in $P$. aeruginosa is mediated by various adhesions and secreted toxins, proteases, effector proteins and pigments that facilitate adhesion, modulate or disrupt host cell pathways, and, target the extracellular matrix. Figure has been recreated from Hauser and Ozer (2011). Abbreviations: ADP, adenosine diphosphate; Asialo-GM1, asialo-gangliotetraocyl ceramide 1; EF2, elongation factor 2; FpvA, feeric pyoverdine receptor; PA, phosphatidic acid; RAS, ribosyltransferase; SOD1, superoxide dismutase 1; 14-3-3, 14-3-3 protein family.

\subsection{Flagellum}

The single unsheathed polar flagellum of $P$. aeruginosa is responsible for the swimming motility of this organism (Kohler, Curty, Barja, van Delden, \&Pechere, 2000). Nonetheless, its role in virulence goes beyond simple motility. Flagellar proteins have been shown to play critical roles in attachment, invasion, biofilm formation and the mediation of inflammatory responses. Flagellar protein synthesis, assembly and regulation 
involves more than 40 genes and is intricately controlled through transcriptional and post-translational events by the four primary regulators RpoN, FleQ, FleR and FliA (Dasgupta et al., 2003).

Non-flagellated mutants are often isolated from chronic infections in CF patients (Mahenthiralingam, Campbell, \& Speert, 1994) due to the repressor activity of AlgT, which acts on the FleQ regulator (Tart, Wolfgang, \& Wozniak, 2005). The loss of flagella in these isolates is believed to be useful for the invasion of the host immune system. Flagellin mediators the inflammatory response via the innate immune system, through its specific interaction with a number of pattern recognition receptors (PRRs) of the host (Verma, Arora, Kuravi, \& Ramphal, 2005). Flagellin is recognized by both TLR5 (Hayashi et al., 2001) and NLRC4 (Franchi et al., 2007; Cohen, \& Prince, 2013); as well NLRP3 (Kim \& Jo, 2013). However, different amino acid residues of flagellin were critical for sensing by NLRC4 and TLR5 (Franchi et al., 2007). Moreover, cytosolic delivery of $P$. aeruginosa flagellin is required for the activation of NLRC4 (Miao, Ernst, Dors, Mao, \& Aderem, 2008). Surprisingly, the NLRC4 inflammasome can be activated independently of flagellin. The flagellin-deficient strains of $P$. aeruginosa can efficiently activate caspase-1 in an NLRC4-dependent manner. This discrepancy as to the requirement for flagellin in NLRC4 inflammasome activation was recently explained in an elegant study by Maio and colleagues (Miao et al., 2010). They found the NLRC4 inflammasome was activated in response to the basal body rod component of the T3SS apparatus from P. aeruginosa (Pscl), as well as, other microorganisms; such as S. typhimurium (PrgJ), Burkholderia pseudomallei (BsaK), Escherichia coli (EprJ and EscI), S. flexneri (MxiL) (Miao et al., 2010). These rod proteins contain a sequence motif that resembles one found in flagellin; hence, NLRC4 is activated by both of these similar stimuli. Furthermore, flagellar vaccines have been investigated in pre-clinical studies in mouse models and have reached phase III clinical trials for CF patients; however, limited protection was observed with a monovalent vaccine and development of a bivalent vaccine has been terminated (Doring \& Pier, 2008).

\subsection{Type IV Pili}

The type IV pili of $P$. aeruginosa have a role in adhesion to many cell types and this is likely important in such phenomena as tissue tropism (attachment to particular tissues), initiation of biofilm formation and non-opsonic phagocytosis, which is mediated by phagocyte receptors that recognize corresponding adhesions on microbial surfaces (Barken et al., 2008; Mahenthiralingam \& Speert, 1995; Punsalang \& Sawyer, 1973). Several studies have indicated a direct correlation between the presence of glycosphingolipid on host cells and $P$. aeruginosa adherence, thus demonstrating the role of this glycosphingolipid as a bacterial receptor. In particular, $P$. aeruginosa pili bind to glycosphingolipid contained within host epithelial cell membranes; ganglio-N-tetraosylceramide (asialo-GM1) (Comolli, Waite, Mostov, \& Engel, 1999). The interaction of pili and asialo-GM1 is mediated the internalization of $P$. aeruginosa in host epithelial cells. In addition, these pili also mediate twitching motility, a factor found to be important in the formation of biofilms in vitro (Klausen et. al., 2003); as well as, in the initiation of dissemination from an initial point of colonization (Hahn, 1997, Klausen et. al., 2003). Although more than 50 genes have been identified to play either a direct or indirect role in the synthesis, functioning and control of the type IV pili of $P$. aeruginosa, the pili are composed of a single type IV pilim protein encoded by pilA (Hansen \& Forest, 2006). Five alleles of pilA have been identified with group I pili being the most prevalent in CF and environmental isolates (Kus, Tullis, Cvitkovitch, \& Burrows, 2004). P. aeruginosa pilin, the major component of the type IV bacterial pilus, is identified as an inflammasome-activator factor (Cecilia, Arlehamn, \& Evans, 2011); as purified pilin activated caspase- 1 and led to secretion of mature IL-1 $\beta$.

\subsection{Type III Secretion System}

P. aeruginosa has a variety of secretion systems of which at least four likely play a role in virulence (Type I, II, III, and IV). One of the most intriguing is T3SS that involves a flagellum-basal-body related system for delivering proteins directly from the cytoplasm of $P$. aeruginosa into the cytosol of host cells. A functional T3SS contributes to the successful evasion of phagocytosis by $P$. aeruginosa as well as damage to host tissues, promotion of immune avoidance and bacterial dissemination. The T3SS of $P$. aeruginosa delivers up to four cytotoxins ExoS, ExoT, ExoU and ExoY, directly to host cells (Frank, 1997; Goranson, Hovey, \& Frank, 1997; Yahr, Mende-Mueller, Friese, \& Frank, 1997).

ExoS and ExoT are bifunctional cytotoxins that possess both Rho GTPase-activating protein and ADP ribosyltransferase activities. These molecules can inhibit phagocytosis by disrupting actin cytoskeletal rearrangement, focal adhesions and signal transduction (Barbieri \& Sun, 2004). Moreover, ExoU is a phospholipase that contributes directly to acute cytotoxicity towards epithelial cells and macrophages; while ExoY is an adenylate cyclase that affects intracellular cAMP levels and cytoskeleton reorganization (Sato \& Frank, 2004; Yahr, Vallis, Hancock, Barbieri, \&Frank, 1998). Recent evidence has implicated a role for the 
T3SS in virulence in humans. The presence of large amount of T3SS products, particularly ExoU, in $P$. aeruginosa cultures from intubated patients was linked to increased mortality regardless of whether these patients had symptoms or confirmation of VAP (Zhuo et al., 2008). Also, P. aeruginosa T3SS activates NLR inflammasome. However, in the absence of any of the known effector proteins, $P$. aeruginosa T3SS apparatus is sufficient to trigger the activation of caspase-1 by the inflammasome via NLRC4 (Hauser, 2009). In another words, a functional T3SS is critical for the induction of caspase-1 activity, IL- $1 \beta$ secretion and cell death, whereas the effectors ExoS, ExoT and ExoY are dispensable (Franchi et al., 2007).

\subsection{Exotoxin A}

There are several critical virulence factors that are secret through Type II secretion mechanism, which use a pilus-like apparatus to secrete proteins into the extracellular environment, including exotoxin A, lipase, phospholipase, alkaline phosphatase, and protease; animal experiments have indicated the significant role of these factors in model infection (Passador \& Iglewski, 1994). For example, exotoxin A has been demonstrated to be involved in local tissue damage and invasion. This cytotoxin is encoded by the gene toxA and has been found to be present in most clinical isolates of $P$. aeruginosa, although its role in virulence is poorly understood (Passador \& Iglewski, 1994). Besides, exotoxin A enters host cells by receptor-mediated endocytosis and catalyzes the ADP-ribosylation of eukaryotic elongation factor-2 (EF-2) (Iglewski, Liu, \& Kabat, 1977). EF-2 inhibits protein synthesis, which ultimately leading to cellular death.

\subsection{Proteases}

$P$. aeruginosa produces several secreted proteases including the zinc metalloprotease (elastase) LasB, the metalloendopeptidase LasA, and alkaline protease. These proteases work in a concerted fashion to destroy host tissue; thus, play a significant role in both acute lung infections and in burn wound infections (Bielecki, Glik, Kawecki, \& Martins dos Santos, 2008; Galloway, 1991; Rumbaugh, Griswold, \& Hamood, 2000). A definite role of these destructive proteases in acute infections has been established. LasA and LasB elastases have also been found in the sputum of CF patients suffering from pulmonary exacerbations of infection (Hollsing, Granstrom, Vasil, Wretlind, \& Strandvik, 1987; Jagger et al., 1982); yet, their role in chronic infection is not well understood.

\subsection{Alginate}

$P$. aeruginosa can produce a mucoid exopolysaccharide capsule, comprised of alginate, an acetylated random co-polymer of $\beta$ 1-4 linked D-mannuronic acid (poly-M) and L-guluronic acid (Gacesa \& Wusteman, 1990). The overproduction of alginate is believed to play a role in cell adherence within the CF lung and is also thought to be involved in resistance to host defense by reducing susceptibility to phagocytosis (Pier, Coleman, Grout, Franklin, \& Ohman, 2001), also in resistance to antibiotics. The small minorities of CF patients, who are carrying only nonmucoid $P$. aeruginosa, have significantly better lung function over time compared to those patients infected with mucoid $P$. aeruginosa (Parad, Gerard, Zurakowski, Nichols, \& Pier, 1999). The tendency of $P$. aeruginosa to change to a mucoid phenotype is one of the most striking and clinically relevant features of infection by this bacterium. Additionally, poly-M shares with LPS the ability to stimulate human monocytes to cytokines production; in a CD-14-dependent manner (Otterlei et al., 1993). Involvement of TLR2 and TLR4 in cell activation by poly-M has been studied in primary murine macrophages (Flo et al., 2002).

\subsection{Quorum Sensing}

Quorum sensing is a mechanism of bacterial "cell-to-cell" communication via diffusible chemical compounds. A critical number of bacteria (the quorum) are required to produce a sufficient amount of a secreted signal molecule (termed an autoinducer) to trigger expression of a large regulon (Diggle, Cornelis, Williams, \& Camara, 2006; Heurlier et al., 2004; Smith, Harris, Phipps, \& Iglewski, 2002). Quorum sensing and biofilm development are two social phenomena exhibited by bacteria. The connection between quorum sensing and biofilms has been named sociomicrobiology (Bjarnsholt et al., 2005; Parsek \& Greenberg, 2005). In addition, P. aeruginosa is regarded as a "model organism" in the quorum sensing field, which studied in the most detail. Quorum sensing is known to control a number of bacterial genes. More than 300 genes are regulated during quorum sensing in $P$. aeruginosa (Schuster et al., 2003).

The most common class of autoinducer used by Gram-negative bacteria is acyl-homoserine lactones (AHL), which diffuse freely across bacterial membranes. AHL signals produced by $P$. aeruginosa are oxohexanoyl-homoserine lactone and butanoyl-homoserine lactone (Pearson et al., 1994; Pearson et al., 1995). AHL signals produce by AHL synthase (LasI/RhlI), which diffuse into the environment. Increasing in bacterial density during infection leads to an increase in autoinducer concentration. When autoinducer reaches a particular 
threshold, it subsequently binds to transcriptional activator (LasR/RhlR) forming a complex that activates genes involved in biofilm formation and coding virulence factors (Kipnis, Sawa, \& Wiener-Kronish, 2006; Davies et al., 1998; Hirakawa \& Tomita, 2013). The production of virulence factors, such as extracellular enzymes and cellular lysins (e.g. rhamnolipid) are important for the pathogenesis of infections as a protective shield against phagocytes (Jensen et al., 2007; Van Gennip et al., 2009; Alhede et al., 2009). Quorum sensing has been shown to determine the tolerance of P. aeruginosa biofilms to antibiotic therapy (Bjarnsholt et al., 2005).

Recent advances in the understanding of quorum sensing in $P$. aeruginosa have generated interest in using quorum sensing as a target for therapeutics. The macrolide antibiotic, azithromycin, has been a promising candidate in this regard as it has been demonstrated to be capable of both penetrating biofilms and interfering with quorum sensing (Hoffmann et al., 2007).

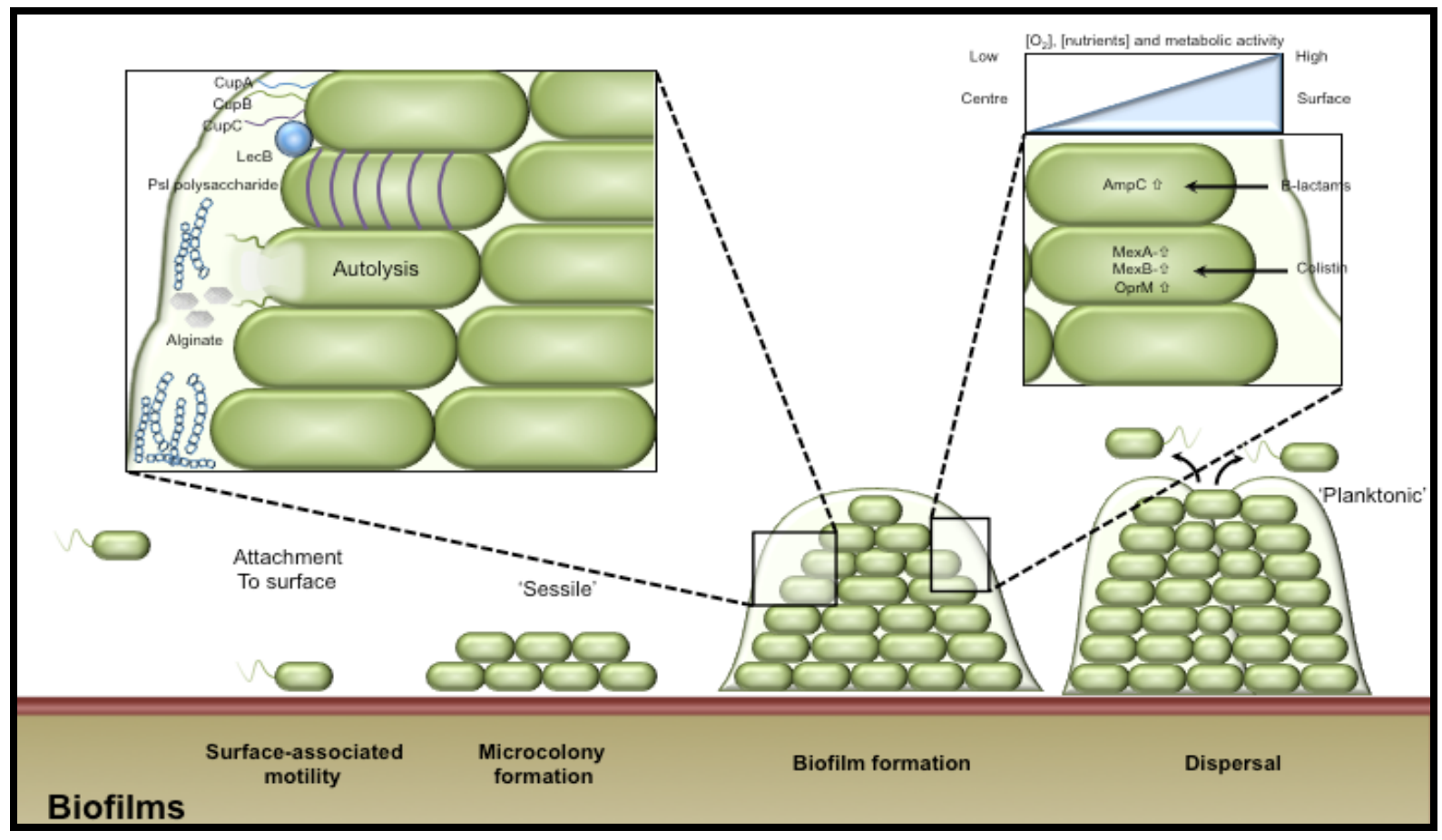

Figure 2. Development of a P. aeruginosa biofilm

Biofilm formation starts with the attachment of free-swimming bacteria (planktonic) to a surface via their type IV pili and flagellum, followed by twitching motility and the formation of microcolonies; then quorum sensing signals begin to accumulate. Once a critical threshold of quorum sensing signals is reached, microcolonies become encased in an extracellular matrix. Cells enter a sessile phase of growth and become highly resistant to antimicrobials, which evolve into mature biofilms. Biofilm architecture depends on the production of the biofilm matrix, which consists of the polysaccharides Pel (synthesized by PelA-PelG), Psl (arranged in a helical pattern around cells) and alginate, extracellular DNA (eDNA), and proteins, including the CupA, CupB and CupC fimbriae, which mediate bacterial attachment during initial biofilm formation, and the lectin LecB. The extracellular polymeric matrix delays diffusion of some antibiotics into the biofilm. A gradient of oxygen and nutrients induces the formation of distinct bacterial subpopulations that vary in their susceptibility to antibiotics; exposure to $\beta$-lactams or colistin can cause the production of resistance factors (AmpC $\beta$-lactamase and MexA-MexB-OprM efflux pumps). Rhamnolipids on bacteria at the surface induce necrosis of neutrophils. Finally, planktonic bacteria are released from parts of a mature biofilm. Individual cells and small microcolonies slough from the mature biofilm initiating further biofilm development. Figure has been recreated from Hauser and Ozer (2011).

\subsection{Biofilm Formation}

P. aeruginosa is capable of forming complex structures called biofilms. Resistance to antimicrobial agents is the most important features of biofilm infections. Biofilm development is a complex process and partly controlled by quorum sensing signals (Figure 2). Furthermore, a variety of components play a role in the initial attachment 
of cells to the surface and development of biofilm matrix including extracellular DNA (eDNA)(Whitchurch, Tolker-Nielsen, Ragas, and Mattick. 2002), exopolysaccharide (Psl, Pel, and alginate) (Ma et al., 2009; Karatan \& Watnick, 2009), iron siderophore pyoverdine, biosurfactant rhamnolipid (Harmsen, Yang, Pamp, Tolker-Nielsen, 2010), and proteinaceous surface appendages such as type IV pili, flagella (Klausen, Aaes-Jorgensen, Molin, \& Tolker-Nielsen, 2003), Cup fimbria (Vallet et al., 2001). Nevertheless, there are still numerous factors that are involved in biofilm formation process and dispersion, which are related to signals, regulatory networks, and materials, reviewed elsewhere (Harmsen, Yang, Pamp, Tolker-Nielsen, 2010; Wei \& Ma, 2013; Karatan \& Watnick, 2009).

During biofilm formation, cell differentiation occurs, and oxygen and water-filled channels are formed to provide nutrition to the deep-rooted cells of the mature biofilm (Davies, 2002; Friedman and Kolter, 2004; Kirisits, Prost, Starkey, \& Parsek, 2005; Ryder, Byrd, \& Wozniak, 2007). P. aeruginosa has been demonstrated to form biofilms on a variety of indwelling medical devices (Choong \& Whitfield, 2000; Khoury, Lam, Ellis, \& Costerton, 1992). It is particularly problematic for patients requiring mechanical ventilation and catheterization, as the surfaces of medical devices can readily develop $P$. aeruginosa biofilms that are difficult to remove. Also, P. aeruginosa has been demonstrated to grow as a biofilm within the body particularly at the site of burn wounds. It has been proposed that $P$. aeruginosa exists as a biofilm in the CF lung (Consterton, Stewart, \& Greenberg, 1999; Singh et. al., 2000) and this has been observed in a mouse model of CF lung infection (Hoffmann et al., 2005).

In addition to evasion of the host immune system, the highly antibiotic resistant nature of biofilms to killing by bactericidal antibiotics contributes to bacterial persistence in chronic infections (Mah, Pitts, Pellock, Walker, Stewart, \& O'Toole, 2003). It has been demonstrated that cells growing in a biofilm can be up to 1000 fold more resistant to antibiotics than free-swimming, planktonic cells (Hoyle \& Costerton, 1991). Biofilms present not only a diffusion barrier to antibiotics, but also the cells in a biofilm have been demonstrated to have significantly different expression patterns compared to their planktonic counterparts (Sauer, Camper, Ehrlich, Costerton, \& Davies, 2002).

\subsection{Type VI Secretion Systems}

Bacterial pathogens frequently possess number of secretion systems that function to translocate protein secretion. The T6SS represents one of the most recently recognized examples of these secretion systems. An interest in T6SS has led to its rapid study in $P$. aeruginosa in term of structure, mechanical function, assembly, and regulation of secretion (Mougous et al., 2006; Ho, Dong, \& Mekalanos, 2014). P. aeruginosa T6SS provides defense against other bacteria in the environment (Ho, Dong, \& Mekalanos, 2014; Russell, Peterson, \& Mougous, 2014) and facilitates interactions with other eukaryotic (Jiang, Waterfield, Yang, Yang, \& Jin, 2014). P. aeruginosa encodes three distinct T6SS, which are known as H1-, H2-, and H3-T6SS, each involved in bacterium's interaction with other organisms. The H1-T6SS delivers at least six toxic effectors into host bacteria and is a model for studying physiological function of T6SS antimicrobial activity (Ho, Dong, \& Mekalanos, 2014; Russell, Peterson, \& Mougous, 2014; Whitney et al., 2014). H2- and H3-T6SS have a dual role allowing interaction with both eukaryotic and prokaryotic target cells. The antibacterial activities mediate through H2-T6SS-dependent phospholipase D (PLD) PldA and H3-T6SS-dependent PldB. Both T6SS effectors, PldA and PldB, can degrade membrane phospholipids, resulting in antibacterial activity. T6SSs, H2-T6SS-dependent PldA and H3-T6SS-dependent PldB, have also been linked to P. aeruginosa immune evasion by promoting internalization into human epithelial cells (Jiang, Waterfield, Yang, Yang, \& Jin, 2014). Interestingly, mutations in the catalytic domains of both PldA and PldB reduced $P$. aeruginosa internalization into epithelial cells, which shows that phospholipase activity is essential for invasion of the mammalian epithelium by P. aeruginosa (Jiang, Waterfield, Yang, Yang, \& Jin, 2014).

Previous works have shown that the internalization of $P$. aeruginosa is dependent on the activation of the eukaryotic phosphoinositide 3-kinase (PI3K), which results in AKT phosphorylation in presence of phosphatidic acid subsequent actin rearrangement and protrusion formation (Jiang, Waterfield, Yang, Yang, \& Jin, 2014; Sana et al., 2012; Kierbel, Gassama-Diagne, Mostov, \& Engel, 2005). In addition, PI3K/AKT signaling pathway is crucial to a range of cellular processes including cell growth, proliferation, and programmed cell death (Krachler, Woolery, \& Orth, 2011). Notably, epithelial cells that were infected with P. aeruginosa mutants (PldA, PldB, H2-T6SS, or H3-T6SS deficient) displayed reduced levels of AKT phosphorylation compared with the wild type strain. Furthermore, PldA and PldB were shown to bind to AKT, and both PldA-AKT and PldB-AKT complexes localized close to the epithelial cell plasma membrane (Jiang, Waterfield, Yang, Yang, \& Jin, 2014). These data suggest that PldA and PldB have a central role in the activation of the PI3K-AKT signaling pathway to promote the invasion of epithelial cells by $P$. aeruginosa. Whereas $P$. aeruginosa is known to colonize the lungs of CF patients, previous studies have indicated that PldB and H3-T6SS loci are both up-regulated under low-oxygen conditions (Alvarez-Ortega \& Harwood, 2007) and also during biofilm formation (Dötsch et al., 2012). For this 
reason, induction of both PldB and H3-T6SS in these conditions may allow better colonization of the lung epithelium through invasion. These findings reveal a function for the $P$. aeruginosa H3-T6SS effector PldB and show that PldB and PldA can influence both bacterial competition and interaction with mammalian hosts. T6SSs are promising targets for the development of new approaches to diagnosis, vaccine development and antimicrobial drug design (Yahr, 2006; Baron \& Coombes, 2007).

\subsection{Oxidant Generation in the Airspace}

Oxidative stress refers to an imbalance in the redox status of the cell favoring an oxidizing environment. Extensive reactive oxygen species (ROS) production leads to the depletion of antioxidants and results in cellular damage. In particular, ROS can damage DNA strands by reacting with base pairs and the deoxyribose phosphate backbone of DNA, the primary target of radical damage (Gram, 1997). Without the protection of antioxidants, ROS can also initiate lipid peroxidation of polyunsaturated fatty acid components of cell membrane phospholipids, affecting cellular integrity (Rahman \& Adcock, 2006). Amino acids can also be damaged by ROS, leading to protein denaturation and enzyme deactivation (Gram, 1997; Rahman \& Adcock, 2006). When left unmanaged, oxidative stress can eventually lead to cell death.

During the infectious process, $P$. aeruginosa induces ROS production within epithelial cells in a few ways. Following its secretion into the microenvironment, pyocyanin permeates the epithelial cell membrane and directly oxidizes intracellular pools of NADPH and glutathione, producing superoxide and downstream ROS (Rada, Gardina, Myers, \& Leto, 2011). Recognition of P. aeruginosa LPS by the epithelial cells leads to ROS production through protein kinase $\mathrm{C}$ (PKC)-NADPH oxidase signaling pathway in human epithelial cells (Yan, $\mathrm{Li}$, Jono, Li, Zhang, Li, \& Shen, 2008). Other potential sources of ROS are derived from the activated epithelium via induction of the mitochondrial electron transport chain, cytochrome p450, and xanthine oxidase. In the case of mechanical ventilation, the introduction of excess oxygen can also fuel the production of ROS (Chow, Herrera, Suzuki, \& Downey, 2003). In acute lung injury, however, stimulated phagocytes produce the majority of ROS (Ward, 2010). Overwhelming oxidant injury may lead to alveolar collapse and extensive fibrotic scarring, impairing gas exchange between the affected airways and the capillary system (Ward, 2010).

\section{Antimicrobial Resistance}

$P$. aeruginosa can be an especially challenging organism to treat once infection has been established as it is intrinsically resistant to many of the available antibiotics. Three mechanisms have been studied by which $P$. aeruginosa resist the action of antibiotics. The outer membrane of $P$. aeruginosa is restricted the penetration of antibiotics and the efficient removal of antibiotics molecules by efflux pumps before acting on their targets. $P$. aeruginosa has the genetic capacity to inactivate and modify of antibiotics. This bacterium can become resistant through mutational changes in antibiotic's targets (Lambert, 2002). Consequently, P. aeruginosa has now achieved the status superbug. This section will provide an overview of the main mechanisms of resistance present in clinical isolates of $P$. aeruginosa.

\subsection{Intrinsic Resistance}

P. aeruginosa exhibits intrinsic resistance to almost all of the available antibiotics, indicating that the wild-type strain possesses number of genetic mechanisms that contribute to reducing susceptibility of the organisms. One of the major factors contributing to this intrinsic resistance is the low permeability of its outer membrane. The outer membrane is essential for passively determining the rate of uptake of antibiotics and small molecules (Hancock, 1998). However, by itself this is insufficient to mediate significant resistance, and antibiotics will equilibrate across the outer membrane. Thus, intrinsic resistance arises from the combination of slow uptake and secondary mechanisms that benefit from this slow uptake including degradative enzymes such as periplasmic $\beta$-lactamase and particularly multidrug efflux systems. There are at least four antibiotic efflux systems have been described including MexAB-OprM and MexXY-OprM, MexCD-OprI, and MexEF-oprN elsewhere (Hancock, 1998; Poole, 2001; Lamber, 2002; Lister, Wolter, \& Hanson, 2009).

The $P$. aeruginosa outer membrane is an asymmetric membrane composed of an inner leaflet of phospholipid, predominantly phosphatidylethanolamine, an outer layer of polyanionic LPS. The latter presents a negatively charged surface, which, together with the divalent cations bridging the individual LPS molecules, forms a matrix around the cell that is relatively impermeable to polar compounds except polycations (Hancock, 1997). Multidrug efflux pumps also mediated resistance to many classes of antibiotics. The P. aeruginosa genome contains a large number of drug efflux systems (Stover et al., 2000), which have been categorized into five superfamilies include: the small multidrug resistance family, the ATP-binding cassette family, the multidrug and toxic compound extrusion family, the resistance-nodulation-cell division family, and major facilitator 
superfamily (Gotoh, Itoh, Tsujimoto, Yamagishi, Oyamada, \& Nishino, 1994; Kohler, Michea-Hamzehpour, Plesiat, Kahr, \& Pechere, 1997; Masuda, Sakagawa, Ohya, Gotoh, Tsujimoto, \& Nishino, 2000; Masuda, Sakagawa, Ohya, Gotoh, Tsujimoto, \& Nishino, 2000; Lister, Wolter, \& Hanson, 2009).

$P$. aeruginosa also expresses periplasmic $\beta$-lactamases to degrade $\beta$-lactan antibiotics. $\beta$-lactamases are hydrolyzing enzymes that cleave the lactam ring of penicillins, carbapenems, cephalosporins and monobactams, thus leading to inactivation of the antibiotic (Richmond and Sykes, 1973; Sanders, 1992; Sykes and Matthew, 1976). In P. aeruginosa, this activity is due to a chromosomally encoded AmpC $\beta$-lactamase. The AmpC $\beta$-lactamase of $P$. aeruginosa can degrade and contribute to intrinsic resistance to ticarcillin, piperacillin and the third-generation cephalosporins. It is strongly induced by carbapenems, particularly imipenem, although these inducing carbapenems are stable against its hydrolytic activity (Balasubramanian et al., 2012).

\subsection{Adaptive Resistance}

Discrepancies between in in vitro susceptibility of $P$. aeruginosa isolates and treatment outcomes in CF patients have been observed, and, can be attributed to the phenomenon of adaptive resistance. Adaptive resistance occurs when cell populations are exposed to non-lethal concentrations of antibiotic and undergo specific changes in gene expression that result in reduced susceptibility. It is a form of inducible resistance that does not require the presence of mutations; it has been demonstrated in in vitro using CF isolates and in mouse models, when isolates were pre-incubated with subinhibitory concentrations of antibiotics (Barclay, Begg, Chambers, Thornley, Pattemore, \& Grimwood, 1996; Brazas and Hancock, 2005; Gilleland, Gilleland, Gibson, \& Champlin, 1989). However, the concern arises that this induction may allow small population to survive and acquire stably resistant mutations. Similarly, polymyxin susceptibility in P. aeruginosa is associated with the LPS structure, which is determined by arnBCADTEF and modulated by PhoPQ and PmrAB (Barrow and Kwon, 2009). Adaptive resistance to polymyxins and antimicrobial peptides has been shown to occur through altered expression of the PhoPQ and PmrAB systems in response to these agents. This also leads to modulation of Lipid A fatty acid composition (Moskowitz, Ernst, \& Miller, 2004), which ultimately affects resistance to not only polymyxin and antimicrobial peptides, but also the aminoglycosides, which rely on the LPS binding for self-promoted uptake.

\subsection{P. aeruginosa as a Superbug}

The accumulation of multiple resistance mechanisms in clinical isolates of $P$. aeruginosa has resulted in strains that are resistance to all available antibiotics. This pandrug resistance, which means resistant to all antimicrobial agents, together with high attributable mortality, has thrust $P$. aeruginosa into the spotlight as an emerging superbug. According to report by the National Nosocomial Infections Surveillance (NNIS) System, which focused on nosocomial infections in ICU, not only were resistance rates increasing, but the incidence of occurrence of most infection types was also increasing (Gaynes and Edwards, 2005). In 2003, the NNIS reported a $9 \%$ increase in resistance to the third generation cephalosporins, a $15 \%$ increase in ciprofloxacin resistance, and most alarming, a $47 \%$ increase in imipenem resistance over a five year period. According to the European Antimicrobial Resistance Surveillance System 18\% of $P$. aeruginosa isolates were multidrug resistance with 6\% of all isolates being resistant to piperacillin, ceftazidime, fluoroquinolones, aminoglycosides and carbapenems (Souli, Galani, \& Giamarellou, 2008). The drug of last resort for infections with multidrug resistance $P$. aeruginosa is colistin (polymyxin E), and while resistance rates remain low (approximately $1 \%$ in most countries), mortality of $80 \%$ has been observed for infections caused by colistin resistance Gram-negative bacilli (Beno, Krcmery, \& Demitrovicova, 2006).

\section{Conclusion}

In conclusion, it would be impossible to remove P. aeruginosa from the environment, even the internal environment of the hospital because it is so hardy and metabolically versatile. However, the last two decades have seen a remarkable addition to active medication and therapy to the regimen for treating CF lung infection. These therapies have enhanced the overall health of patients with CF and, they are apparently part of the reason that demanded survival has increased. However, these therapies do not offer a cure and they primarily treat downstream complications of the pathophysiology of CF lung infection, meaning that patients persist to undergo the morbidity associated with chronic airway infection; predicted survival still lags well below what is normal. However, innate immunity is critical in protecting the host from bacterial invasion, but at the same time it can directly \& indirectly damage tissues. In addition, these therapies add to a considerable treatment burden and are thus also associated with poor adherence. What is more, it appears likely that the antibiotic resistance will continue to be a problem in dealing with $P$. aeruginosa infections. The fundamental issues underlying this problem are the condition of the patients that are prone to such infections, and, the high intrinsic resistance of 
this bacterium, which have remained constant. Chronic P. aeruginosa airway infection and the accompanying inflammatory response are clearly the significant clinical problems for CF patients today. Instead, we need an urgent alternative therapeutic strategy.

\section{Acknowledgment}

This work was supported by scholarship award granted to A. Alhazmi, from Jazan University, through Saudi Arabian Cultural Bureau in Canada.

\section{References}

Alhede, M., Bjarnsholt, T., Jensen, P. Ø., Phipps, R. K., Moser, C., Christophersen, L., ... \& Givskov, M. (2009). Pseudomonas aeruginosa recognizes and responds aggressively to the presence of polymorphonuclear leukocytes. Microbiology, 155(11), 3500-3508. http://dx.doi.org/10.1099/mic.0.031443-0

Altoparlak, U., Erol, S., Akcay, M. N., Celebi, F., \& Kadanali, A. (2004). The timerelated changes of antimicrobial resistance patterns and predominant bacterial profiles of burn wounds and body flora of burned patients. Burns, 30, 660-664. http://dx.doi.org/10.1016/j.burns.2004.03.005

Alvarez - Ortega, C., \& Harwood, C. S. (2007). Responses of Pseudomonas aeruginosa to low oxygen indicate that growth in the cystic fibrosis lung is by aerobic respiration. Molecular microbiology, 65(1), 153-165. http://dx.doi.org/10.1111/j.1365-2958.2007.05772.x

Baker, C. C., Miller, C. L., \& Trunkey, D. D. (1979). Predicting fatal sepsis in burn patients. J Trauma, 19, 641-648. http://dx.doi.org/0022-5282/79/1909-0641\$02.00/0

Balasubramanian, D, Schneper, L, Merighi, M, Smith, R, \& Narasimhan, G. (2012). The Regulatory Repertoire of Pseudomonas aeruginosa AmpC B-Lactamase Regulator AmpR Includes Virulence Genes. PLoS ONE, 7(3), e34067. http://dx.doi.org/10.1371/journal.pone.0034067

Bals, R., Weiner, D. J., \& Wilson, J. M. (1999). The innate immune system in cystic fibrosis lung disease. J Clin Invest, 103, 303-7. http://dx.doi.org/10.1172/JCI6277

Bang, R. L., Sharma, P. N., Sanyal, S. C., \& Al Najjadah, I. (2002). Septicaemia after burn injury: a comparative study. Burns, 28, 746-51. http://dx.doi.org/10.1016/S0305-4179(02)00183-3

Barbieri, J. T., \& Sun, J. 2004. Pseudomonas aeruginosa ExoS and ExoT. Rev Physiol Biochem Pharmacol 152:79-92. http://dx.doi.org/10.1007/s10254-004-0031-7

Barclay, M. L., Begg, E. J., Chambers, S. T., Thornley, P. E., Pattemore, P. K., \& Grimwood, K. (1996). Adaptive resistance to tobramycin in Pseudomonas aeruginosa lung infection in cystic fibrosis. J Antimicrob Chemother, 37, 1155-64. http://dx.doi.org/10.1093/jac/37.6.1155

Barken, K. B., Pamp, S. J., Yang, L., Gjermansen, M., Bertrand, J. J., Klausen, M., ... \& Tolker - Nielsen, T. (2008). Roles of type IV pili, flagellum - mediated motility and extracellular DNA in the formation of mature multicellular structures in Pseudomonas aeruginosa biofilms. Environmental microbiology, 10(9), 2331-2343. http://dx.doi.org/10.1111/j.1462-2920.2008.01658.x

Baron, C., \& Coombes, B. (2007). Targeting bacterial secretion systems: benefits of disarmament in the microcosm. Infectious Disorders-Drug Targets (Formerly Current Drug Targets-Infectious Disorders), 7(1), 19-27. http://dx.doi.org/10.2174/187152607780090685

Barret, J. P., \& Herndon, D. N. (2003). Effects of burn wound excision on bacterial colonization and invasion. Plastic and reconstructive surgery, 111(2), 744-50. http://dx.doi.org/10.1097/01.PRS.0000041445.76730.23

Barrow, K., \& Kwon, D. H. (2009). Alterations in two-component regulatory systems of phoPQ and pmrAB are associated with polymyxin B resistance in clinical isolates of Pseudomonas aeruginosa. Antimicrob Agents Chemother, 53(12), 5150-5154. http://dx.doi.org/10.1128/AAC.00893-09

Barrow, R. E., Spies, M., Barrow, L. N., \& Herndon, D. N. (2004). Influence of demographics and inhalation injury on burn mortality in children. Burns, 30, 72-7. http://dx.doi.org/10.1016/j.burns.2003.07.003

Beno, P., Krcmery, V., \& Demitrovicova, A. (2006). Bacteraemia in cancer patients caused by colistin-resistant Gram-negative bacilli after previous exposure to ciprofloxacin and/or colistin. Clin Microbiol Infect, 12, 497-8. http://dx.doi.org/10.1111/j.1469-0691.2006.01364.x

Bielecki, P., Glik, J., Kawecki, M., \& dos Santos, V. A. M. (2008). Towards understanding Pseudomonas aeruginosa burn wound infections by profiling gene expression. Biotechnology letters, 30(5), 777-790. http://dx.doi.org/10.1007/s10529-007-9620-2 
Bjarnsholt, T., Jensen, P. Ø., Burmølle, M., Hentzer, M., Haagensen, J. A., Hougen, H. P., ... \& Givskov, M. (2005). Pseudomonas aeruginosa tolerance to tobramycin, hydrogen peroxide and polymorphonuclear leukocytes is quorum-sensing dependent. Microbiology, 151(2), 373-383. http://dx.doi.org/10.1099/mic.0. 27463-0

Bjarnsholt, T., Jensen, P. Ø., Burmølle, M., Hentzer, M., Haagensen, J. A., Hougen, H. P., ... \& Givskov, M. (2005). Pseudomonas aeruginosa tolerance to tobramycin, hydrogen peroxide and polymorphonuclear leukocytes is quorum-sensing dependent. Microbiology, 151(2), 373-383. http://dx.doi.org/10.1099/mic.0. 27463-0

Blondel-Hill, E., \& Fryters, S. (2006). Bugs and Drugs, vol. Capital Health, Edmonton.

Bobadilla J, Jr M, Fine, J., \& Farrell, P. (2002). Cystic Fibrosis: A Worldwide Analysis of CFTR Mutations -Correlation With Incidence Data and Application to Screening. Human Mutation, 19, 575-606. http://dx.doi.org/10.1002/humu.10041

Bodey, G. P., Jadeja, L., \& Elting, L. (1985). Pseudomonas bacteremia: retrospective analysis of 410 episodes. Archives of Internal Medicine, 145(9), 1621-1629. http://dx.doi.org/10.1001/archinte.1985.00360090089015

Brazas, M. D., \& Hancock, R. E. W. (2005). Ciprofloxacin induction of a susceptibility determinant in Pseudomonas aeruginosa. Antimicrob Agents Chemother, 49, 3222-7. http://dx.doi.org/10.1128/AAC.49.8. 3222-3227.2005

Chastre, J., \& Fagon, J. Y. (2002). Ventilator-associated pneumonia. Am J Respir Crit Care Med, 165, 867-903. http://dx.doi.org/10.1164/ajrccm.165.7.2105078

Choong, S., \& Whitfield, H. (2000). Biofilms and their role in infections in urology. BJU Int, 86, 935-41. http://dx.doi.org/10.1046/j.1464-410x.2000.00949.x

Church, D., Elsayed, S., Reid, O., Winston, B., \& Lindsay, R. (2006). Burn wound infections. Clin Microbiol Rev, 19, 403-34. http://dx.doi.org/10.1128/CMR.19.2.403-434.2006

Cobb, L. M., Mychaleckyj, J. C., Wozniak, D. J., \& Lopez-Boado, Y. S. (2004). Pseudomonas aeruginosa flagellin and alginate elicit very distinct gene expression patterns in airway epithelial cells: implications for cystic fibrosis disease. J Immunol, 173, 5659-70. http://dx.doi.org/10.4049/jimmunol.173.9.5659

Cohen, T. S., Prince, A. S. (2013). Activation of inflammasome signaling mediates pathology of acute P: aeruginosa pneumonia. $J$ Clin Invest., 123, 1630-1637. http://dx.doi.org/10.1172/JCI66142

Collins, F. S. (1992). Cystic fibrosis: molecular biology and therapeutic implications. Science, 256, 774-779. http://dx.doi.org/10.1126/science.256.5058.774

Comolli, J. C., Waite, L. L., Mostov, K. E., \& Engel, J. N. (1999). Pili binding to asialo-GM1 on epithelial cells can mediate cytotoxicity or bacterial internalization byPseudomonas aeruginosa. Infection and immunity, 67(7), 3207-3214.

Costerton, J. W., Stewart, P. S., \& Greenberg, E. P. (1999). Bacterial biofilms: a common cause of persistent infections. Science, 284, 1318-22. http://dx.doi.org/10.1126/science.284.5418.1318

Dasgupta, N., Wolfgang, M. C., Goodman, A. L., Arora, S. K., Jyot, J., Lory, S., \& Ramphal, R. (2003). A four tiered transcriptional regulatory circuit controls flagellar biogenesis in Pseudomonas aeruginosa. Molecular microbiology, 50(3), 809-824. http://dx.doi.org/10.1046/j.1365-2958.2003.03740.x

Davies, D. G., Parsek, M. R., Pearson, J. P., Iglewski, B. H., Costerton, J. W., \& Greenberg, E. P. (1998). The involvement of cell-to-cell signals in the development of a bacterial biofilm. Science, 280(5361), 295-298. http://dx.doi.org/10.1126/science.280.5361.295

Davies, J. C. (2002). Pseudomonas aeruginosa in cystic fibrosis: pathogenesis and persistence. Paediatr Respir Rev, 3, 128-34. http://dx.doi.org/10.1016/S1526-0550(02)00003-3

Diggle, S. P., Cornelis, P., Williams, P., \& Camara, M. (2006). 4-quinolone signalling in Pseudomonas aeruginosa: old molecules, new perspectives. Int J Med Microbiol, 296, 83-91. http://dx.doi.org/10.1016/j.ijmm.2006.01.038

DiMango, E., Zar, H. J., Bryan, R., Prince, A. (1995). Diverse Pseudomonas aeruginosa products stimulate respiratory epithelial cells to produce interleukin-8. J Clin Invest., 96, 2204-10. http://dx.doi.org/10.1172/ JCI1 18275

Doggett, R. G. (1969). Incidence of mucoid Pseudomonas aeruginosa from clinical sources. Appl Microbiol, 18, 936-7.

Doggett, R. G. (1979). Microbiology of Pseudomonas aeruginosa. In R. G. Doggett (Ed.), Pseudomonas aeruginosa: Clinical Manifestations of Infection and Current Therapy (pp. 1-8). New York: Academic Press. 
Doggett, R. G., Harrison, G. M., \& Carter, R. E. (1971). Mucoid Pseudomonas aeruginosa in patients with chronic illnesses. Lancet, 1, 236-7. http://dx.doi.org/10.1016/S0140-6736(71)90973-1

Donaldson, S. H., Bennett, W. D., Zeman, K. L., Knowles, M. R., Tarran, R., \& Boucher, R. C. (2006). Mucus clearance and lung function in cystic fibrosis with hypertonic saline. $N$ Engl $J$ Med, 354, 241-50. http://dx.doi.org/10.1056/NEJMoa043891

Doring, G., \& Pier, G. B. (2008). Vaccines and immunotherapy against Pseudomonas aeruginosa. Vaccine, 26, 1011-24. http://dx.doi.org/10.1016/j.vaccine.2007.12.007

Döring, G., Bragonzi, A., Paroni, M., Akturk, F. F., Cigana, C., Schmidt, A., ... Ulrich, M. (2014). BIIL 284 reduces neutrophil numbers but increases $\mathrm{P}$. aeruginosa bacteremia and inflammation in mouse lungs. $J$ Cyst Fibros, 13(2), 156-163. http://dx.doi.org/10.1016/j.jcf.2013.10.007

Döring, G., Conway, S. P., Heijerman, H. G. M., Hodson, M. E., Høiby, N., Smyth, A., ... \& Consensus Committee. (2000). Antibiotic therapy against Pseudomonas aeruginosa in cystic fibrosis: a European consensus. European Respiratory Journal, 16(4), 749-767. http://dx.doi.org/10.1034/j.1399-3003.2000. 16d30.x

Dötsch, A., Eckweiler, D., Schniederjans, M., Zimmermann, A., Jensen, V., Scharfe, M., ... \& Häussler, S. (2012). The Pseudomonas Aeruginosa Transcriptome in Planktonic Cultures and Static Biofilms Using Rna Sequencing. Plos One, 7(2), E31092. http://dx.doi.org/10.1371/journal.pone.0031092

Ernst, R. K., Moskowitz, S. M., Emerson, J. C., Kraig, G. M., Adams, K. N., Harvey, M. D., ... \& Miller, S. I. (2007). Unique lipid A modifications in Pseudomonas aeruginosa isolated from the airways of patients with cystic fibrosis. Journal of Infectious Diseases, 196(7), 1088-1092. http://dx.doi.org/10.1086/521367

Fagon, J. Y., Chastre, J., Hance, A. J., Montravers, P., Novara, A., \& Gibert, C. (1993). Nosocomial pneumonia in ventilated patients: a cohort study evaluating attributable mortality and hospital stay. The American journal of medicine, 94(3), 281-288. http://dx.doi.org/10.1016/0002-9343(93)90060-3

Faure, K., Fujimoto, J., Shimabukuro, D. W., Ajayi, T., Shime, N., Moriyama, K., ... \& Sawa, T. (2003). Effects of monoclonal anti-PcrV antibody on Pseudomonas aeruginosa-induced acute lung injury in a rat model. Journal of immune based therapies and vaccines, 1(1), 2. http://dx.doi.org/10.1186/1476-8518-1-2

Favero, M. S., Carson, L. A., Bond, W. W., \& Petersen, N. J. (1971). Pseudomonas aeruginosa: growth in distilled water from hospitals. Science, 173(3999), 836-838. http://dx.doi.org/10.1126/science.173.3999.836

Fishman, L. S., \& Armstrong, D. (1972). Pseudomonas aeruginosa bacteremia in patients with neoplastic disease. Cancer, 30, 764-73. http://dx.doi.org/10.1002/1097-0142(197209)30:3<764::AID-CNCR2820300326>3.0.CO; $2-\mathrm{G}$

Flo, T. H., Ryan, L., Latz, E., Takeuchi, O., Monks, B. G., Lien, E., ... \& Espevik, T. (2002). Involvement of toll-like receptor (TLR) 2 and TLR4 in cell activation by mannuronic acid polymers. Journal of Biological Chemistry, 277(38), 35489-35495. http://dx.doi.org/10.1074/jbc.M201366200

Foweraker, J. E., Laughton, C. R., Brown, D. F. J., \& Bilton, D. (2005). Phenotypic variability of Pseudomonas aeruginosa in sputa from patients with acute infective exacerbation of cystic fibrosis and its impact on the validity of antimicrobial susceptibility testing. Journal of Antimicrobial Chemotherapy, 55(6), 921-927. http://dx.doi.org/10.1093/jac/dki146

Franchi, L., Muñoz-Planillo, R., \& Núñez, G. (2012). Sensing and reacting to microbes through the inflammasomes. Nat Immunol., 13, 325-32. http://dx.doi.org/10.1038/ni.2231

Franchi, L., Stoolman, J., Kanneganti, T. D., Verma, A., Ramphal, R., \& Núñez, G. (2007). Critical role for Ipaf in Pseudomonas aeruginosa - induced caspase - 1 activation. European journal of immunology, 37(11), 3030-3039. http://dx.doi.org/10.1002/eji.200737532

Frank, D. W. (1997). The exoenzyme S regulon of Pseudomonas aeruginosa. Mol Microbiol, 26, 621-9. http://dx.doi.org/10.1046/j.1365-2958.1997.6251991.x

Frederiksen, B., Koch, C., \& Hoiby, N. (1997). Antibiotic treatment of initial colonization with Pseudomonas aeruginosa postpones chronic infection and prevents deterioration of pulmonary function in cystic fibrosis. Pediatr Pulmonol, 23, 330-335. http://dx.doi.org/10.1002/(SICI)1099-0496(199705)23:5<330::AID-PPUL4 $>3.0 . \mathrm{CO} ; 2-\mathrm{O}$

Freeman, L. (1916). Chronic General Infection with the Bacillus Pyocyaneus. Ann Surg, 64,195-202. 
Friedman, L., \& Kolter, R. (2004). Genes involved in matrix formation in Pseudomonas aeruginosa PA14 biofilms. Mol Microbiol, $\quad$ 51, 675-90. http://dx.doi.org/10.1002/(SICI)1099-0496(199705)23:5<330:: AID-PPUL4>3.0.CO;2-O

Fuqua, C., \& Greenberg, E. P. (2002). Listening in on bacteria: acyl-homoserine lactone signalling. Nat Rev Mol Cell Biol, 3, 685-95. http://dx.doi.org/10.1038/nrm907

Gacesa, P., \& Wusteman, F. S. (1990). Plate assay for simultaneous detection of alginate lyases and determination of substrate specificity. Appl Environ Microbiol, 56, 2265-2267.

Galloway, D. R. (1991). Pseudomonas aeruginosa elastase and elastolysis revisited: recent developments. Mol Microbiol, 5, 2315-21. http://dx.doi.org/10.1111/j.1365-2958.1991.tb02076.x

Gaynes, R., \& Edwards, J. R. (2005). Overview of nosocomial infections caused by gram-negative bacilli. Clin Infect Dis, 41, 848-54. http://dx.doi.org/10.1086/432803

Gibson, R. L., Burns, J. L., \& Ramsey, B. W. (2003). Pathophysiology and management of pulmonary infections in cystic fibrosis. Am J Respir Crit Care Med, 168, 918-51. http://dx.doi.org/10.1164/rccm.200304-505SO

Gilleland, L. B., Gilleland, H. E., Gibson, J. A., \& Champlin, F. R. (1989). Adaptive resistance to aminoglycoside antibiotics in Pseudomonas aeruginosa. Journal of medical microbiology, 29(1), 41-50. http://dx.doi.org/10.1099/00222615-29-1-41

Goranson, J., Hovey, A. K., \& Frank, D. W. (1997). Functional analysis of exsC and exsB in regulation of exoenzyme S production by Pseudomonas aeruginosa. Journal of bacteriology, 179(5), 1646-1654.

Gotoh, N., Itoh, N., Tsujimoto, H., Yamagishi, J. I., Oyamada, Y., \& Nishino, T. (1994). Isolation of OprM deficient mutants of Pseudomonas aeruginosa by transposon insertion mutagenesis: Evidence of involvement in multiple antibiotic resistance. FEMS microbiology letters, 122(3), 267-273. http://dx.doi.org/10.1111/j. 1574-6968.1994.tb07179.x

Govan, J. R., \& Deretic, V. (1996). Microbial pathogenesis in cystic fibrosis: mucoid Pseudomonas aeruginosa and Burkholderia cepacia. Microbiol Rev, 60, 539-74.

Gram. (1997). Chemically reactive intermediates and pulmonary xenobiotic toxicity. Pharmacol rev, 49(4), 297-341.

Greene, C. M., Carroll, T. P., Smith, S. G., Taggart, C. C., Devaney, J., Griffin, S., ... \& McElvaney, N. G. (2005). TLR-induced inflammation in cystic fibrosis and non-cystic fibrosis airway epithelial cells. The Journal of Immunology, 174(3), 1638-1646. http://dx.doi.org/10.4049/jimmunol.174.3.1638

Grimwood, K. (1992). The pathogenesis of Pseudomonas aeruginosa lung infections in cystic fibrosis. J Paediatr Child Health, 28, 4-11. http://dx.doi.org/10.1111:j.1440-1754.1992.tb02609.x

Hahn, H. P. W. (1997). The type-4 pilus is the major virulence-associated adhesin of Pseudomonas aeruginosa--a review. Gene, 192, 99-108. http://dx.doi.org/10.1016/S0378-1119(97)00116-9

Hancock, R. E. W. (1997). The bacterial outer membrane as a drug barrier. Trends Microbiol, 5, 37-42. http://dx.doi.org/10.1016/S0966-842X(97)81773-8

Hancock, R. E. W. (1998). Resistance mechanisms in Pseudomonas aeruginosa and other nonfermentative gram-negative bacteria. Clinical Infectious Diseases, 27(Supplement 1), S93-S99. http://dx.doi.org/10.1086/ 514909

Hancock, R. E., Mutharia, L. M., Chan, L., Darveau, R. P., Speert, D. P., \& Pier, G. B. (1983). Pseudomonas aeruginosa isolates from patients with cystic fibrosis: a class of serum-sensitive, nontypable strains deficient in lipopolysaccharide $\mathrm{O}$ side chains. Infection and Immunity, 42(1), 170-177.

Hanessian, S., Regan, W., Watson, D., \& Haskell, T. H. (1971). Isolation and characterization of antigenic components of a new heptavalent Pseudomonas vaccine. Nat New Biol, 229, 209-10. http://dx.doi.org/10.1038/newbio229209a0

Hansen, J. K., \& Forest, K. T. (2006). Type IV pilin structures: insights on shared architecture, fiber assembly, receptor binding and type II secretion. J Mol Microbiol Biotechnol, 11, 192-207. http://dx.doi.org/10.1159/ 000094054

Harmsen, M., Yang, L., Pamp, S. J., \& Tolker - Nielsen, T. (2010). An update on Pseudomonas aeruginosa biofilm formation, tolerance, and dispersal. FEMS Immunology \& Medical Microbiology, 59(3), 253-268. 
Hauser, A. R. (2009). The type III secretion system of Pseudomonas aeruginosa: infection by injection. Nature Reviews Microbiology, 7(9), 654-665. http://dx.doi.org/10.1038/nrmicro2199

Hauser, R. A., \& Ozer, A. E. (2011). Pseudomonas aeruginosa. Nature Review Microbiology, 9(3). Poster produced with support from Cubist Pharmaceuticals.

Häußler, S., Ziegler, I., Löttel, A., Götz, F. V., Rohde, M., Wehmhöhner, D., ... \& Steinmetz, I. (2003). Highly adherent small-colony variants of Pseudomonas aeruginosa in cystic fibrosis lung infection. Journal of medical microbiology, 52(4), 295-301. http://dx.doi.org/10.1099/jmm.0.05069-0

Hayashi, F., Smith, K. D., Ozinsky, A., Hawn, T. R., Yi, E. C., Goodlett, D. R., ... \& Aderem, A. (2001). The innate immune response to bacterial flagellin is mediated by Toll-like receptor 5. Nature, 410(6832), 1099-1103. http://dx.doi.org/10.1038/35074106

Heine, H., Rietschel, E. T., \& Ulmer, A. J. 2001. The biology of endotoxin. Mol Biotechnol, 19, 279-96. http://dx.doi.org/10.1385/MB:19:3:279

Henrichfreise, B., Wiegand, I., Pfister, W., \& Wiedemann, B. 2007. Resistance mechanisms of multiresistant Pseudomonas aeruginosa strains from Germany and correlation with hypermutation. Antimicrob Agents Chemother, 51, 4062-70. http://dx.doi.org/10.1128/AAC.00148-07

Heurlier, K., Williams, F., Heeb, S., Dormond, C., Pessi, G., Singer, D., ... \& Haas, D. (2004). Positive control of swarming, rhamnolipid synthesis, and lipase production by the posttranscriptional RsmA/RsmZ system in Pseudomonas aeruginosa PAO1. Journal of bacteriology, 186(10), 2936-2945. http://dx.doi.org/10.1128/JB.186.10.2936-2945.2004

Hidron, A. I., Edwards, J. R., Patel, J., Horan, T. C., Sievert, D. M., Pollock, D. A., \& Fridkin, S. K. (2008). Antimicrobial - resistant pathogens associated with healthcare - associated infections: annual summary of data reported to the National Healthcare Safety Network at the Centers for Disease Control and Prevention, 2006-2007. infection control and hospital epidemiology, 29(11), 996-1011. http://dx.doi.org/10.1086/591861

Hirakawa, H., \& Tomita, H. (2013). Interference of bacterial cell-to-cell communication: a new concept of antimicrobial chemotherapy breaks antibiotic resistance. Frontiers in microbiology, 4. http://dx.doi.org/10.3389/fmicb.2013.00114

Ho, B. T., Dong, T. G., \& Mekalanos, J. J. (2014). A view to a kill: the bacterial type VI secretion system. Cell host \& microbe, 15(1), 9-21. http://dx.doi.org/10.1016/j.chom.2013.11.008

Hodson, M. E. (2000). Treatment of cystic fibrosis in the adult. Respiration, 67, 595-607. http://dx.doi.org/10.1159/000056287

Hodson, M., Penketh, A. R. L., \& Batten, J. C. (1981). Aerosol carbenicillin and gentamicin treatment of Pseudomonas aeruginosa infection in patients with cystic fibrosis. The Lancet, 318(8256), 1137-1139. http://dx.doi.org/10.1016/S0140-6736(81)90588-2

Hoffmann, N., Lee, B., Hentzer, M., Rasmussen, T. B., Song, Z., Johansen, H. K., ... \& Høiby, N. (2007). Azithromycin blocks quorum sensing and alginate polymer formation and increases the sensitivity to serum and stationary-growth-phase killing of Pseudomonas aeruginosa and attenuates chronic P. aeruginosa lung infection in Cftr-/- mice. Antimicrobial agents and chemotherapy, 51(10), 3677-3687. http://dx.doi.org/10.1128/ AAC.01011-06

Hoffmann, N., Rasmussen, T. B., Jensen, P., Stub, C., Hentzer, M., Molin, S., ... \& Høiby, N. (2005). Novel mouse model of chronic Pseudomonas aeruginosa lung infection mimicking cystic fibrosis. Infection and immunity, 73(4), 2504-2514. http://dx.doi.org/10.1128/IAI.73.8.5290.2005

Hogardt, M., Hoboth, C., Schmoldt, S., Henke, C., Bader, L., \& Heesemann, J. (2007). Stage-specific adaptation of hypermutable Pseudomonas aeruginosa isolates during chronic pulmonary infection in patients with cystic fibrosis. Journal of Infectious Diseases, 195(1), 70-80. http://dx.doi.org/10.1086/509821

Hollsing, A. E., Granström, M., Vasil, M. L., Wretlind, B., \& Strandvik, B. (1987). Prospective study of serum antibodies to Pseudomonas aeruginosa exoproteins in cystic fibrosis. Journal of clinical microbiology, 25(10), 1868-1874.

Hoshino, K., Takeuchi, O., Kawai, T., Sanjo, H., Ogawa, T., Takeda, Y., ... \& Akira, S. (1999). Cutting edge: Toll-like receptor 4 (TLR4)-deficient mice are hyporesponsive to lipopolysaccharide: evidence for TLR4 as the Lps gene product. The Journal of Immunology, 162(7), 3749-3752. 
Hoyle, B. D., \& Costerton, J. W. (1991). Bacterial resistance to antibiotics: the role of biofilms. Prog Drug Res, 37, 91-105.

Hudson, V. L., Wielinski, C. L., \& Regelmann, W. E. (1993). Prognostic implications of initial oropharyngeal bacterial flora in patients with cystic fibrosis diagnosed before the age of two years. J Pediatr, 122, 854-60. http://dx.doi.org/10.1016/S0022-3476(09)90007-5

Iglewski, B. H., Liu, P. V., \& Kabat, D. A. V. I. D. (1977). Mechanism of action of Pseudomonas aeruginosa exotoxin Aiadenosine diphosphate-ribosylation of mammalian elongation factor 2 in vitro and in vivo. Infection and immunity, 15(1), 138-144.

Irvin, R. T., Govan, J. W., Fyfe, J. A., \& Costerton, J. W. (1981). Heterogeneity of antibiotic resistance in mucoid isolates of Pseudomonas aeruginosa obtained from cystic fibrosis patients: role of outer membrane proteins. Antimicrobial agents and chemotherapy, 19(6), 1056-1063. http://dx.doi.org/10.1128/AAC.19.6.1056

Jagger, K. S., Robinson, D. L., Franz, M. N., \& Warren, R. L. (1982). Detection by enzyme-linked immunosorbent assays of antibody specific for Pseudomonas proteases and exotoxin A in sera from cystic fibrosis patients. Journal of clinical microbiology, 15(6), 1054-1058.

Jensen, P. Ø., Bjarnsholt, T., Phipps, R., Rasmussen, T. B., Calum, H., Christoffersen, L., ... \& Høiby, N. (2007). Rapid necrotic killing of polymorphonuclear leukocytes is caused by quorum-sensing-controlled production of rhamnolipid by Pseudomonas aeruginosa. Microbiology, 153(5), 1329-1338. http://dx.doi.org/10.1099/ mic.0.2006/003863-0

Jiang, F., Waterfield, N. R., Yang, J., Yang, G., \& Jin, Q. (2014). A Pseudomonas Aeruginosa Type Vi Secretion Phospholipase D Effector Targets both Prokaryotic and Eukaryotic Cells. Cell Host \& Microbe, 15(5), 600-610. http://dx.doi.org/10.1016/j.chom.2014.04.010

Karatan, E., \& Watnick, P. (2009). Signals, regulatory networks, and materials that build and break bacterial biofilms. Microbiology and Molecular Biology Reviews, 73(2), 310-347. http://dx.doi.org/10.1128/MMBR. 00041-08

Khoury, A. E., Lam, K., Ellis, B., \& Costerton, J. W. (1992). Prevention and control of bacterial infections associated with medical devices. ASAIO journal, 38(3), M174-M178.

Kierbel, A., Gassama-Diagne, A., Mostov, K., \& Engel, J. N. (2005). The Phosphoinositol-3-Kinase-Protein Kinase B/Akt Pathway is Critical for Pseudomonas Aeruginosa Strain Pak Internalization. Molecular Biology of the Cell, 16(5), 2577-2585. http://dx.doi.org/10.1091/mbc.e04-08-0717

Kim, J. J., \& Jo, E. K. (2013). NLRP3 inflammasome and host protection against bacterial infection. Journal of Korean medical science, 28(10), 1415-1423. http://dx.doi.org/10.3346/jkms.2013.28.10.1415

Kipnis, E., Sawa, T., \& Wiener-Kronish, J. (2006). Targeting mechanisms of Pseudomonas aeruginosa pathogenesis. Medecine et maladies infectieuses, 36(2), 78-91. http://dx.doi.org/10.1016/j.medmal.2005.10.007

Kirisits, M. J., Prost, L., Starkey, M., \& Parsek, M. R. (2005). Characterization of colony morphology variants isolated from Pseudomonas aeruginosa biofilms. Applied and environmental microbiology, 71(8), 4809-4821. http://dx.doi.org/10.1128/AEM.71.8.4809-4821.2005

Kirisits, M. J., Prost, L., Starkey, M., \& Parsek. M. R. (2005). Characterization Of Colony Morphology Variants Isolated From Pseudomonas Aeruginosa Biofilms. Appl Environ Microbiol, 71, 4809-21. http://dx.doi.org/10.1128/aem.71.8.4809-4821.2005

Klausen, M., Aaes - Jørgensen, A., Molin, S., \& Tolker - Nielsen, T. (2003). Involvement of bacterial migration in the development of complex multicellular structures in Pseudomonas aeruginosa biofilms. Molecular microbiology, 50(1), 61-68. http://dx.doi.org/10.1046/j.1365-2958.2003.03677.x

Klausen, M., Heydorn, A., Ragas, P., Lambertsen, L., Aaes - Jørgensen, A., Molin, S., \& Tolker - Nielsen, T. (2003). Biofilm formation by Pseudomonas aeruginosa wild type, flagella and type IV pili mutants. Molecular microbiology, 48(6), 1511-1524. http://dx.doi.org/10.1046/j.1365-2958.2003.03525.x

Kobayashi, M., Yoshida, T., Takeuchi, D., Jones, V. C., Shigematsu, K., Herndon, D. N., \& Suzuki, F. (2008). Gr-1+ CD11b+ cells as an accelerator of sepsis stemming from Pseudomonas aeruginosa wound infection in thermally injured mice. Journal of leukocyte biology, 83(6), 1354-1362. http://dx.doi.org/10.1189/jlb.0 807541

Köhler, T., Curty, L. K., Barja, F., van Delden, C., \& Pechère, J. C. (2000). Swarming of Pseudomonas aeruginosa is dependent on cell-to-cell signaling and requires flagella and pili. Journal of bacteriology, 182(21), 5990-5996. http:/dx.doi.org/10.1128/JB.182.21.5990-5996.2000 
Köhler, T., Michea-Hamzehpour, M., Plesiat, P., Kahr, A. L., \& Pechere, J. C. (1997). Differential selection of multidrug efflux systems by quinolones in Pseudomonas aeruginosa. Antimicrobial agents and chemotherapy, 41(11), 2540-2543.

Kollberg, H., Mossberg, B., Afzelius, B. A., Philipson, K., \& Camner, P. (1977). Cystic fibrosis compared with the immotile-cilia syndrome. A study of mucociliary clearance, ciliary ultrastructure, clinical picture and ventilatory function. Scandinavian journal of respiratory diseases, 59(6), 297-306. http://dx.doi.org/10. 1172/JCI7124

Krachler, A. M., Woolery, A. R., \& Orth, K. (2011). Manipulation of Kinase Signaling by Bacterial Pathogens. The Journal of Cell Biology, 195(7), 1083-1092. http://dx.doi.org/10.1083/jcb.201107132

Kurahashi, K., Kajikawa, O., Sawa, T., Ohara, M., Gropper, M. A., Frank, D. W., ... \& Wiener-Kronish, J. P. (1999). Pathogenesis of septic shock in Pseudomonas aeruginosa pneumonia. The Journal of clinical investigation, 104(6), 743-750.

Kus, J. V., Tullis, E., Cvitkovitch, D. G., \& Burrows, L. L. (2004). Significant differences in type IV pilin allele distribution among Pseudomonas aeruginosa isolates from cystic fibrosis (CF) versus non-CF patients. Microbiology, 150(5), 1315-1326. http://dx.doi.org/10.1099/mic.0.26822-0

Lambert, P. A. (2002). Mechanisms of antibiotic resistance in Pseudomonas aeruginosa. Journal of the Royal Society of Medicine, 95(Suppl 41), 22.

Lamkanfi, M., \& Dixit, V. M. (2009). The inflammasomes. PLoS pathogens, 5(12), e1000510. http://dx.doi.org/10.1371/journal.ppat.1000510

Langford, D. T., \& Hiller, J. (1984). Prospective, controlled study of a polyvalent Pseudomonas vaccine in cystic fibrosis--three year results. Arch Dis Child, 59, 1131-4. http://dx.doi.org/10.1136/adc.59.12.1131

Lartigau, A. J. (1898). A contribution to the study of the pathogenesis of the Bacillus Pyocyaneus, with special reference to its relation to an epidemic of dysentery. J Exp Med, 3, 595-609.

Lindestam Arlehamn, C. S., \& Evans, T. J. (2011). Pseudomonas aeruginosa pilin activates the inflammasome. Cellular microbiology, 13(3), 388-401. http://dx.doi.org/10.1111/j.1462-5822.2010.01541.x

Lister, P. D., Wolter, D. J., \& Hanson, N. D. (2009). Antibacterial-resistant Pseudomonas aeruginosa: clinical impact and complex regulation of chromosomally encoded resistance mechanisms. Clinical microbiology reviews, 22(4), 582-610. http://dx.doi.org/10.1128/CMR.00040-09

Liu, P. V., \& Wang, S. (1990). Three new major somatic antigens of Pseudomonas aeruginosa. J Clin Microbiol, $28,922-5$.

Lyczak, J. B., Cannon, C. L., \& Pier, G. B. (2000). Establishment of Pseudomonas aeruginosa infection: lessons from a versatile opportunist. Microbes Infect, 2, 1051-60. http://dx.doi.org/10.1016/S1286-4579(00)01259-4

Ma, L., Conover, M., Lu, H., Parsek, M. R., Bayles, K., \& Wozniak, D. J. (2009). Assembly and development of the Pseudomonas aeruginosa biofilm matrix. PLoS pathogens, 5(3), e1000354. http://dx.doi.org/10.1371/ journal.ppat. 1000354

Maceachran, D. P., Ye, S., Bomberger, J. M., Hogan, D. A., Swiatecka-Urban, A., Stanton, B. A., \& O'Toole, G. A. (2007). The Pseudomonas aeruginosa secreted protein PA2934 decreases apical membrane expression of the cystic fibrosis transmembrane conductance regulator. Infect Immun, 75(8), 3902-3912. http://dx.doi.org/10. 1128/IAI.00338-07

MacLeod, D. L., Nelson, L. E., Shawar, R. M., Lin, B. B., Lockwood, L. G., Dirks, J. E., ... \& Garber, R. L. (2000). Aminoglycoside-resistance mechanisms for cystic fibrosis Pseudomonas aeruginosa isolates are unchanged by long-term, intermittent, inhaled tobramycin treatment. Journal of Infectious Diseases, 181(3), 1180-1184. http://dx.doi.org/10.1086/315312

MacMillan, B. G. (1980). Infections following burn injury. Surg Clin North Am, 60, 185-96.

Mah, T. F., Pitts, B., Pellock, B., Walker, G. C., Stewart, P. S., \& O'Toole, G. A. (2003). A genetic basis for Pseudomonas aeruginosa biofilm antibiotic resistance. Nature, 426(6964), 306-310. http://dx.doi.org/10.1038/ nature 02122

Mahenthiralingam, E., \& Speert, D. P. (1995). Nonopsonic phagocytosis of Pseudomonas aeruginosa by macrophages and polymorphonuclear leukocytes requires the presence of the bacterial flagellum. Infect Immun, $63,4519-23$. 
Mahenthiralingam, E., Campbell, M. E., \& Speert, D. P. (1994). Nonmotility and phagocytic resistance of Pseudomonas aeruginosa isolates from chronically colonized patients with cystic fibrosis. Infection and Immunity, 62(2), 596-605.

Masuda, N., Sakagawa, E., Ohya, S., Gotoh, N., Tsujimoto, H., \& Nishino, T. (2000). Contribution of the MexX-MexY-OprM efflux system to intrinsic resistance in Pseudomonas aeruginosa. Antimicrobial agents and chemotherapy, 44(9), 2242-2246.

Masuda, N., Sakagawa, E., Ohya, S., Gotoh, N., Tsujimoto, H., \& Nishino, T. (2000). Substrate specificities of MexAB-OprM, MexCD-OprJ, and MexXY-oprM efflux pumps in Pseudomonas aeruginosa. Antimicrobial agents and chemotherapy, 44(12), 3322-3327. http://dx.doi.org/10.1128/AAC.44.9.2242-2246.2000

Mendelman, P. M., Smith, A. L., Levy, J., Weber, A., Ramsey, B., \& Davis, R. L. (1985). Aminoglycoside penetration, inactivation, and efficacy in cystic fibrosis sputum. The American review of respiratory disease, 132(4), 761-765.

Miao, E. A., Ernst, R. K., Dors, M., Mao, D. P., \& Aderem, A. (2008). Pseudomonas aeruginosa activates caspase 1 through Ipaf. Proc. Natl. Acad. Sci. USA 105, 2562-2567. http://dx.doi.org/10.1073/pnas.0712183105

Miao, E. A., Ernst, R. K., Dors, M., Mao, D. P., \& Aderem, A. (2008). Pseudomonas Aeruginosa activates caspase 1 through Ipaf. Proc. Natl. Acad. Sci. USA 105, 2562-2567. http://dx.doi.org/10.1073/pnas.0712183105

Miao, E. A., Mao, D. P., Yudkovsky, N., Bonneau, R., Lorang, C. G., Warren, S. E., ... \& Aderem, A. (2010). Innate immune detection of the type III secretion apparatus through the NLRC4 inflammasome. Proceedings of the National Academy of Sciences, 107(7), 3076-3080. http://dx.doi.org/10.1073/pnas.0913087107

Moreau-Marquis, S., Stanton, B. A., \& O’Toole, G. A. (2008). Pseudomonas aeruginosa biofilm formation in the cystic fibrosis airway. Pulmonary pharmacology \& therapeutics, 21(4), 595-599. http://dx.doi.org/10.1016/ j.pupt.2007.12.001

Moskowitz, S. M., Ernst, R. K., \& Miller, S. I. (2004). PmrAB, a two-component regulatory system of Pseudomonas aeruginosa that modulates resistance to cationic antimicrobial peptides and addition of aminoarabinose to lipid A. Journal of bacteriology, 186(2), 575-579. http://dx.doi.org/10.1128/JB.186.2. 575-579.2004

Nixon, G. M., Armstrong, D. S., Carzino, R., Carlin, J. B., Olinsky, A., Robertson, C. F., \& Grimwood, K. (2001). Clinical outcome after early Pseudomonas aeruginosa infection in cystic fibrosis. The Journal of pediatrics, 138(5), 699-704. http://dx.doi.org/10.1067/mpd.2001.112897

Oliver, A., Cantón, R., Campo, P., Baquero, F., \& Blázquez, J. (2000). High frequency of hypermutable Pseudomonas aeruginosa in cystic fibrosis lung infection. Science, 288(5469), 1251-1253. http://dx.doi.org/10. 1126/science.288.5469.1251

Otterlei, M., Sundan, A., Skjåk-Bræk, G., Ryan, L., Smidsrød, O., \& Espevik, T. (1993). Similar mechanisms of action of defined polysaccharides and lipopolysaccharides: characterization of binding and tumor necrosis factor alpha induction. Infection and immunity, 61(5), 1917-1925.

Pai, V. B., \& Nahata, M. C. (2001). Efficacy and safety of aerosolized tobramycin in cystic fibrosis. Pediatr Pulmonol, 32, 314-27. http://dx.doi.org/10.1002/ppul.1125

Parad, R. B., Gerard, C. J., Zurakowski, D., Nichols, D. P., \& Pier, G. B. (1999). Pulmonary outcome in cystic fibrosis is influenced primarily by mucoid Pseudomonas aeruginosa infection and immune status and only modestly by genotype. Infection and immunity, 67(9), 4744-4750.

Parsek, M. R., \& Greenberg, E. P. (2005). Sociomicrobiology: the connections between quorum sensing and biofilms. Trends in microbiology, 13(1), 27-33. http://dx.doi.org/10.1016/j.tim.2004.11.007

Passador, L., \& Iglewski, W. (1994). ADP-ribosylating toxins. Methods Enzymol, 235, 617-31. http://dx.doi.org/10. 1016/0076-6879(94)35175-9

Pearson, J. P., Gray, K. M., Passador, L., Tucker, K. D., Eberhard, A., Iglewski, B. H., \& Greenberg, E. P. (1994). Structure of the autoinducer required for expression of Pseudomonas aeruginosa virulence genes. Proceedings of the National Academy of Sciences, 91(1), 197-201. http://dx.doi.org/10.1073/pnas.91.1.197

Pearson, J. P., Passador, L., Iglewski, B. H., \& Greenberg, E. P. (1995). A second N-acylhomoserine lactone signal produced by Pseudomonas aeruginosa. Proceedings of the National Academy of Sciences, 92(5), 1490-1494. http://dx.doi.org/10.1073/pnas.92.5.1490 
Pennington, J. E. (1979). Lipopolysaccharide Pseudomonas vaccine: efficacy against pulmonary infection with Pseudomonas aeruginosa. J Infect Dis, 140, 73-80. http://dx.doi.org/10.1093/infdis/140.1.73

Pennington, J. E., \& Miler, J. J. (1979). Evaluation of a new polyvalent Pseudomonas vaccine in respiratory infections. Infect Immun, 25, 1029-34.

Pier, G. B. (2003). Promises and pitfalls of Pseudomonas aeruginosa lipopolysaccharide as a vaccine antigen. Carbohydr Res, 338, 2549-56. http://dx.doi.org/10.1016/S0008-6215(03)00312-4

Pier, G. B., \& Ames, P. (1984). Mediation of the killing of rough, mucoid isolates of Pseudomonas aeruginosa from patients with cystic fibrosis by the alternative pathway of complement. $J$ Infect Dis, 150, 223-8. http://dx.doi.org/10.1093/infdis/150.2.223

Pier, G. B., \& Ramphal, R. (2005). Pseudomonas aeruginosa. In G. L. Mandell \& J. E. Bennett (Ed.), Mandell, Douglas, and Bennett's principles and practice of infectious diseases (vol. 2, pp. 2587-2615). Elsevier/Churchill Livingstone, New York.

Pier, G. B., Coleman, F., Grout, M., Franklin, M., \& Ohman, D. E. (2001). Role of alginate O acetylation in resistance of mucoid Pseudomonas aeruginosa to opsonic phagocytosis. Infection and immunity, 69(3), 1895-1901. http://dx.doi.org/10.1128/IAI.69.3.1895-1901.2001

Pier, G. B., Grout, M., \& Zaidi, T. S. (1997). Cystic fibrosis transmembrane conductance regulator is an epithelial cell receptor for clearance of Pseudomonas aeruginosa from the lung. Proceedings of the National Academy of Sciences, 94(22), 12088-12093.

Pier, G. B., Grout, M., Zaidi, T. S., Olsen, J. C., Johnson, L. G., Yankaskas, J. R., \& Goldberg, J. B. (1996). Role of mutant CFTR in hypersusceptibility of cystic fibrosis patients to lung infections. Science, 271(5245), 64-67. http://dx.doi.org/10.1126/science.271.5245.64

Poltorak, A., He, X., Smirnova, I., Liu, M. Y., Van Huffel, C., Du, X., ... \& Beutler, B. (1998). Defective LPS signaling in $\mathrm{C} 3 \mathrm{H} / \mathrm{HeJ}$ and $\mathrm{C} 57 \mathrm{BL} / 10 \mathrm{ScCr}$ mice: mutations in Tlr4 gene. Science, 282(5396), 2085-2088. http://dx.doi.org/10.1126/science.282.5396.2085

Poole, K. (2001). Multidrug efflux pumps and antimicrobial resistance in Pseudomonas aeruginosa and related organisms. J Mol Microbiol Biotechnol, 3(2), 255-264.

Preston, M. J., Fleiszig, S. M., Zaidi, T. S., Goldberg, J. B., Shortridge, V. D., Vasil, M. L., \& Pier, G. B. (1995). Rapid and sensitive method for evaluating Pseudomonas aeruginosa virulence factors during corneal infections in mice. Infection and immunity, 63(9), 3497-3501.

Punsalang, A. P., \& Sawyer, W. D. (1973). Role of pili in the virulence of Neisseria gonorrhoeae. Infection and immunity, 8(2), 255-263.

Qureshi, S. T., Larivière, L., Leveque, G., Clermont, S., Moore, K. J., Gros, P., \& Malo, D. (1999). Endotoxin-tolerant mice have mutations in Toll-like receptor 4 (Tlr4). The Journal of experimental medicine, 189(4), 615-625. http://dx.doi.org/10.1084/jem.189.4.615

Rada, B., Gardina, P., Myers, T. G., \& Leto, T. L. (2011). Reactive oxygen species mediate inflammatory cytokine release and egfr-dependent mucin secretion in airway epithelial cells exposed to pseudomonas pyocyanin. Mucosal immunol, 4(2), 158-171. http://dx.doi.org/10.1038/mi.2010.62

Raetz, C. R., \& Whitfield, C. (2002). Lipopolysaccharide endotoxins. Annu Rev Biochem, 71, 635-700. http://dx.doi.org/10.1146/annurev.biochem.71.110601.135414

Rahman, I., \& Adcock, I. M. (2006). Oxidative stress and redox regulation of lung inflammation in COPD. European Respiratory Journal, 28(1), 219-242.

Rahme, L. G., Tan, M. W., Le, L., Wong, S. M., Tompkins, R. G., Calderwood, S. B., \& Ausubel, F. M. (1997). Use of model plant hosts to identify Pseudomonas aeruginosa virulence factors. Proceedings of the National Academy of Sciences, 94(24), 13245-13250.

Ramsey, B. W., Pepe, M. S., Quan, J. M., Otto, K. L., Montgomery, A. B., Williams-Warren, J., ... \& Smith, A. L. (1999). Intermittent administration of inhaled tobramycin in patients with cystic fibrosis. New England Journal of Medicine, 340(1), 23-30. http://dx.doi.org/10.1056/NEJM199901073400104

Ratjen, F., \& Doring, G. (2003). Cystic fibrosis. Lancet, 361, 681-9. http://dx.doi.org/10.1016/S0140-6736 (03)12567-6 
Ratjen, F., Döring, G., \& Nikolaizik, W. H. (2001). Effect of inhaled tobramycin on early Pseudomonas aeruginosa colonisation in patients with cystic fibrosis. The Lancet, 358(9286), 983-984. http://dx.doi.org/10.1016/S0140-6736(01)06124-4

Rello, J., Ricart, M., Mirelis, B., Quintana, E., Gurgui, M., Net, A., \& Prats, G. (1994). Nosocomial bacteremia in a medical-surgical intensive care unit: epidemiologic 61 characteristics and factors influencing mortality in 111 episodes. Intensive Care Med, 20, 94-8. http://dx.doi.org/10.1007/BF01707661

Richmond, M. H., \& Sykes, R. B. (1973). The beta-lactamases of gram-negative bacteria and their possible physiological role. Adv Microb Physiol, 9, 31-88. http://dx.doi.org/10.1016/S0065-2911(08)60376-8

Rosenfeld, M., Ramsey, B. W., \& Gibson, R. L. (2003). Pseudomonas acquisition in young patients with cystic fibrosis: pathophysiology, diagnosis, and management. Curr Opin Pulm Med, 9, 492-7.

Rumbaugh, K. P., Griswold, J. A., \& Hamood, A. N. (2000). The role of quorum sensing in the in vivo virulence of Pseudomonas aeruginosa. Microbes and infection, 2(14), 1721-1731. http://dx.doi.org/10.1016/S12864579(00)01327-7

Ryder, C., Byrd, M., \& Wozniak, D. J. (2007). Role of polysaccharides in Pseudomonas aeruginosa biofilm development. Current opinion in microbiology, 10(6), 644-648. http://dx.doi.org/10.1016/j.mib.2007. 09.010

Salunkhe, P., Smart, C. H., Morgan, J. A. W., Panagea, S., Walshaw, M. J., Hart, C. A., ... \& Winstanley, C. (2005). A cystic fibrosis epidemic strain of Pseudomonas aeruginosa displays enhanced virulence and antimicrobial resistance. Journal of bacteriology, 187(14), 4908-4920. http://dx.doi.org/10.1128/JB.187.14.4908-4920. 2005

Sana, T. G., Hachani, A., Bucior, I., Soscia, C., Garvis, S., Termine, E., ... \& Bleves, S. (2012). The second type VI secretion system of Pseudomonas aeruginosa strain PAO1 is regulated by quorum sensing and Fur and modulates internalization in epithelial cells. Journal of Biological Chemistry, 287(32), 27095-27105. http://dx.doi.org/10.1074/jbc.M112.376368

Sanders, C. C. (1992). beta-Lactamases of gram-negative bacteria: new challenges for new drugs. Clin Infect Dis, 14, 1089-99.62. http://dx.doi.org/10.1093/clinids/14.5.1089

Sato, H., \& Frank, D. W. (2004). ExoU is a potent intracellular phospholipase. Mol Microbiol, 53, 1279-90. http://dx.doi.org/10.1111/j.1365-2958.2004.04194.x

Sauer, K., Camper, A. K., Ehrlich, G. D., Costerton, J. W., \& Davies, D. G. (2002). Pseudomonas aeruginosa displays multiple phenotypes during development as a biofilm. Journal of bacteriology, 184(4), 1140-1154. http://dx.doi.org/10.1128/jb.184.4.1140-1154.2002

Schroeder, T. H., Lee, M. M., Yacono, P. W., Cannon, C. L., Gerçeker, A. A., Golan, D. E., \& Pier, G. B. (2002). CFTR is a pattern recognition molecule that extracts Pseudomonas aeruginosa LPS from the outer membrane into epithelial cells and activates NF-kB translocation. Proceedings of the National Academy of Sciences, 99(10), 6907-6912. http://dx.doi.org/10.1073/pnas.092160899

Schuster, M., Lostroh, C. P., Ogi, T., \& Greenberg, E. P. (2003). Identification, timing, and signal specificity of Pseudomonas aeruginosa quorum-controlled genes: a transcriptome analysis. Journal of bacteriology, 185(7), 2066-2079. http://dx.doi.org/10.1128/JB.185.7.2066-2079.2003

Shimazu, R., Akashi, S., Ogata, H., Nagai, Y., Fukudome, K., Miyake, K., \& Kimoto, M. (1999). MD-2, a molecule that confers lipopolysaccharide responsiveness on Toll-like receptor 4. The Journal of experimental medicine, 189(11), 1777-1782. http://dx.doi.org/10.1084/jem.189.11.1777

Shime, N., Sawa, T., Fujimoto, J., Faure, K., Allmond, L. R., Karaca, T., ... \& Wiener-Kronish, J. P. (2001). Therapeutic administration of anti-PcrV F (ab') 2 in sepsis associated with Pseudomonas aeruginosa. The Journal of Immunology, 167(10), 5880-5886. http://dx.doi.org/10.4049/jimmunol.167.10.5880

Singh, P. K., Schaefer, A. L., Parsek, M. R., Moninger, T. O., Welsh, M. J., \& Greenberg, E. P. (2000). Quorum-sensing signals indicate that cystic fibrosis lungs are infected with bacterial biofilms. Nature, 407(6805), 762-764. http://dx.doi.org/10.1038/35037627

Skerrett, S. J., Wilson, C. B., Liggitt, H. D., \& Hajjar, A. M. (2007). Redundant Toll-like receptor signaling in the pulmonary host response to Pseudomonas aeruginosa. American Journal of Physiology-Lung Cellular and Molecular Physiology, 292(1), L312-L322. http://dx.doi.org/10.1152/ajplung.00250.2006

Smith, R. S., Harris, S. G., Phipps, R., \& Iglewski, B. (2002). The Pseudomonas aeruginosa quorum-sensing molecule N-(3-oxododecanoyl) homoserine lactone contributes to virulence and induces inflammation in vivo. Journal of bacteriology, 184(4), 1132-1139. http://dx.doi.org/10.1128/jb.184.4.1132-1139.2002 
Souli, M., Galani, I., \& Giamarellou, H. (2008). Emergence of extensively drug-resistant and pandrug-resistant Gram-negative bacilli in Europe. Euro surveill, 13(47), 19045.

Speert, D. P., Campbell, M. E., Henry, D. A., Milner, R., Taha, F., Gravelle, A., ... \& Mahenthiralingam, E. (2002). Epidemiology of Pseudomonas aeruginosa in cystic fibrosis in British Columbia, Canada. American journal of respiratory and critical care medicine, 166(7), 988-993. http://dx.doi.org/10.1164/rccm.2203011

Starner, T. D., \& McCray, P. B. (2005). Pathogenesis of early lung disease in cystic fibrosis: a window of opportunity to eradicate bacteria. Annals of internal medicine, 143(11), 816-822. http://dx.doi.org/10.7326/0003-4819-143-11-200512060-

Stead, R. J., Hodson, M. E., \& Batten, J. C. (1987). Inhaled ceftazidime compared with gentamicin and carbenicillin in older patients with cystic fibrosis infected with Pseudomonas aeruginosa. British journal of diseases of the chest, 81, 272-279. http://dx.doi.org/10.1016/0007-0971(87)90161-6

Stover, C. K., Pham, X. Q., Erwin, A. L., Mizoguchi, S. D., Warrener, P., Hickey, M. J., ... \& Olson, M. V. (2000). Complete genome sequence of Pseudomonas aeruginosa PAO1, an opportunistic pathogen. Nature, 406(6799), 959-964. http://dx.doi.org/10.1038/35023079

Stutz, A., Golenbock, D. T., \& Latz, E. (2009). Inflammasomes: too big to miss. The Journal of clinical investigation, 119(12), 3502-3511. http://dx.doi.org/10.1172/JCI40599

Sykes, R. B., \& Matthew, M. (1976). The beta-lactamases of gram-negative bacteria and their role in resistance to beta-lactam antibiotics. J Antimicrob Chemother, 2, 115-57. http://dx.doi.org/10.1093/jac/2.2.115

Tamura, Y., Suzuki, S., \& Sawada, T. (1992). Role of elastase as a virulence factor in experimental Pseudomonas aeruginosa infection in mice. Microbial pathogenesis, 12(3), 237-244. http://dx.doi.org/10.1016/0882-4010(92)90058-V

Tamura, Y., Suzuki, S., Kijima, M., Takahashi, T., \& Nakamura, M. (1992). Effect of proteolytic enzyme on experimental infection of mice with Pseudomonas aeruginosa. J Vet Med Sci, 54, 597-9. http://dx.doi.org/10.1292/jvms.54.597

Tang, H. B., DiMango, E., Bryan, R., Gambello, M., Iglewski, B. H., Goldberg, J. B., \& Prince, A. (1996). Contribution of specific Pseudomonas aeruginosa virulence factors to pathogenesis of pneumonia in a neonatal mouse model of infection. Infection and immunity, 64(1), 37-43.

Tart, A. H., Wolfgang, M. C., \& Wozniak, D. J. (2005). The alternative sigma factor AlgT represses Pseudomonas aeruginosa flagellum biosynthesis by inhibiting expression of fleQ. Journal of bacteriology, 187(23), 7955-7962. http://dx.doi.org/10.1128/JB.187.23.7955-7962.2005

Thuong, M., Arvaniti, K., Ruimy, R., De la Salmoniere, P., Scanvic-Hameg, A., Lucet, J. C., \& Regnier, B. (2003). Epidemiology of Pseudomonas aeruginosa and risk factors for carriage acquisition in an intensive care unit. Journal of Hospital Infection, 53(4), 274-282. http://dx.doi.org/10.1128/JB.187.23.7955-7962. 2005

Trafny, E. A. (1998). Susceptibility of adherent organisms from Pseudomonas aeruginosa and Staphylococcus aureus strains isolated from burn wounds to antimicrobial agents. Int $J$ Antimicrob Agents, 10, 223-8. http://dx.doi.org/10.1016/S0924-8579(98)00042-9

Vallet, I., Olson, J. W., Lory, S., Lazdunski, A., \& Filloux, A. (2001). The chaperone/usher pathways of Pseudomonas aeruginosa: identification of fimbrial gene clusters (cup) and their involvement in biofilm formation. Proceedings of the National Academy of Sciences, 98(12), 6911-6916. http://dx.doi.org/10.1073/pnas.111551898

Van Gennip, M., Christensen, L. D., Alhede, M., Phipps, R., Jensen, P. Ø., Christophersen, L., ... \& Bjarnsholt, T. (2009). Inactivation of the rhlA gene in Pseudomonas aeruginosa prevents rhamnolipid production, disabling the protection against polymorphonuclear leukocytes. Apmis, 117(7), 537-546. http://dx.doi.org/10.1111/j.1600-0463.2009.02466.x

Van Hartingsveldt, J., \& Stouthamer, A. H. (1973). Mapping and characterization of mutants of Pseudomonas aeruginosa affected in nitrate respiration in aerobic or anaerobic growth. Journal of general microbiology, 74(1), 97-106. http://dx.doi.org/10.1099/00221287-74-1-97

Verma, A., Arora, S. K., Kuravi, S. K., \& Ramphal, R. (2005). Roles of specific amino acids in the N terminus of Pseudomonas aeruginosa flagellin and of flagellin glycosylation in the innate immune response. Infection and immunity, 73(12), 8237-8246. http://dx.doi.org/10.1128/IAI.73.12.8237-8246.2005

Ward. (2010). Oxidative stress: acute and progressive lung injury. Ann n y acad sci, 1203, 53-59. 
Wei, Q., \& Ma, L. Z. (2013). Biofilm matrix and its regulation in Pseudomonas aeruginosa. International journal of molecular sciences, 14(10), 20983-21005. http://dx.doi.org/10.3390/ijms141020983

Whitchurch, C. B., Tolker-Nielsen, T., Ragas, P. C., \& Mattick, J. S. (2002). Extracellular DNA required for bacterial biofilm formation. Science, 295(5559), 1487-1487. http://dx.doi.org/10.1126/science.295. 5559.1487

Whitecar Jr, J. P., Lima, M., \& Body, G. P. (1970). Pseudomonas bacteremia in patients with malignant diseases. The American journal of the medical sciences, 260(4), 216-223.

Whitney, J. C., Beck, C. M., Goo, Y. A., Russell, A. B., Harding, B. N., De Leon, J. A., ... \& Mougous, J. D. (2014). Genetically Distinct Pathways Guide Effector Export Through the Type Vi Secretion System. Molecular Microbiology, 92(3), 529-542. http://dx.doi.org/10.1111/mmi.12571

Wright, S. D., Ramos, R. A., Tobias, P. S., Ulevitch, R. J., \& Mathison, J. C. (1990). CD14, a receptor for complexes of lipopolysaccharide (LPS) and LPS binding protein. Science, 249(4975), 1431-1433. http://dx.doi.org/10.1126/science.1698311

Yahr, T. L. (2006). A Critical New Pathway For Toxin Secretion?. New England Journal Of Medicine, 355(11), 1171. http://dx.doi.org/10.1056/nejmcibr063931

Yahr, T. L., Mende-Mueller, L. M., Friese, M. B., \& Frank, D. W. (1997). Identification of type III secreted products of the Pseudomonas aeruginosa exoenzyme S regulon. Journal of bacteriology, 179(22), 7165-7168.

Yahr, T. L., Vallis, A. J., Hancock, M. K., Barbieri, J. T., \& Frank, D. W. (1998). ExoY, an adenylate cyclase secreted by the Pseudomonas aeruginosa type III system. Proceedings of the National Academy of Sciences, 95(23), 13899-13904. http://dx.doi.org/10.1073/pnas.95.23.13899

Yan, F., Li, W., Jono, H., Li, Q., Zhang, S., Li, J. D., \& Shen, H. (2008). Reactive oxygen species regulate pseudomonas aeruginosa lipopolysaccharide-induced muc5ac mucin expression via pkc-nadph oxidase-ros-tgf-alpha signaling pathways in human airway epithelial cells. Biochem biophys res commun, 366(2), 513-519. http://dx.doi.org/10.1016/j.bbrc.2007.11.172

Zhuo, H., Yang, K., Lynch, S. V., Dotson, R. H., Glidden, D. V., Singh, G., ... \& Wiener-Kronish, J. P. (2008). Increased mortality of ventilated patients with endotracheal Pseudomonas aeruginosa without clinical signs of infection. Critical care medicine, 36(9), 2495-2503. http://dx.doi.org/10.1097/CCM.0b013e318183f3f8

\section{Copyrights}

Copyright for this article is retained by the author(s), with first publication rights granted to the journal.

This is an open-access article distributed under the terms and conditions of the Creative Commons Attribution license (http://creativecommons.org/licenses/by/3.0/). 